\title{
Maternity rights and Mothers' Return to Work
}

\author{
Simon Burgess, Paul Gregg, \\ Carol Propper, Elizabeth Washbrook \\ And the ALSPAC Study Team
}

July 2002

\begin{abstract}
In this paper we use the ALSPAC cohort of 12,000 births to examine the effect of maternity rights on mothers' post-birth return to employment decisions. We aim to disentangle the effects of the terms of maternity rights entitlements from the effects of other factors (such as household wealth, personal preferences and labour market opportunities) that influence the timing of a mother's return to work. We adopt a discrete hazard model with instrumental variables to estimate a counterfactual of what mothers with rights would have done in the absence of this legislation. Mothers with rights have an underlying (but unobserved) stronger attachment to the labour market which prompts earlier return than on average. Nevertheless, even when we take this into account we find a substantial impact of maternity rights on behaviour. Having rights induces around 20 per cent more women to return to their previous job before 7 months than would otherwise be the case. Women from lower skilled groups return disproportionately at the date at which maternity pay expires, while managerial and professional women tend to return at the expiry of unpaid leave.
\end{abstract}

JEL Classification: I38, J13, J22,

\section{Acknowledgements}

We thank the Leverhulme Trust for funding this research. We would like to thank the Department for Education and Skills for financial support on this project. Usual disclaimers apply. We would like to thank Marten Lindeboom, Richard Smith and participants at a CMPO internal seminar for comments and suggestions. We are extremely grateful to all the mothers who took part and to the midwives for their cooperation and help in recruitment. The whole ALSPAC Study Team comprises interviewers, computer technicians, laboratory technicians, clerical workers, research scientists, volunteers and managers who continue to make the study possible. This study could not have been undertaken without the financial support of the Medical Research Council, the Wellcome Trust, UK government departments, medical charities and others. The ALSPAC study is part of the WHO initiated European Longitudinal Study of Pregnancy \& Childhood.

\author{
Address for Correspondence \\ Department of Economics \\ University of Bristol \\ 12 Priory Road \\ Bristol \\ BS8 1TN \\ Tel: +44 (0)1179289083 \\ Liz.Washbrook@bristol.ac.uk
}




\section{Introduction}

Maternity rights legislation has been operating in the UK with only minor changes since 1979. Under these rules a mother who has worked with the same employer for two years and who has stopped working later than 11 weeks before the expected due date can take up to 29 weeks leave after the birth and be guaranteed a return to their previous job. For 18 weeks the mother is financially compensated after which any further leave taken is unpaid. In this paper we use a cohort of 12,000 (pregnancies and) births that occurred in the UK county of Avon UK in 1991 and 1992 to examine the effect of maternity rights on mothers' post-birth return to employment decisions. We aim to disentangle the effects of the terms of maternity rights entitlements from the effects of other factors (such as household wealth, personal preferences and labour market opportunities) that influence the timing of a mother's return to work.

This analysis has two key motivations. Firstly, the UK government is in the process of enacting legislation that will extend the lengths of both paid and unpaid leave. Understanding the way in which mothers respond to a given regime of maternity rights should enable us to throw some light on the likely consequences of this policy change. Secondly, in a separate paper we explore the effects of maternal employment on children's cognitive and behavioural outcomes. To the extent that maternity rights policy influences the timing of return to work it potentially has implications for child, as well as maternal, welfare.

Our data clearly show that mothers with maternity rights disproportionately return to work when paid and unpaid leave cease (at 4 and 7 months). So whilst $40 \%$ of all women are back at work by 8 months, this is nearly four times as high (56\% to $12 \%$ ) among those still in employment in the last trimester of the pregnancy (a requirement 
to have rights) than those not. Furthermore, the characteristics of mothers who return at each of these two dates differ, in that less skilled women and those with nonworking partners mainly return when paid leave stops, whereas professional and managerial women with working partners return at 7 months when unpaid leave ends. We adopt a discrete choice hazard model with instrumental variables (IV) to estimate a counterfactual of what mothers with rights would have done in the absence of this legislation. This suggests that mothers with rights have characteristics (such as higher education) that would mean that they would tend to return to work early even without legislation. Furthermore IV estimation suggests that this group had an underlying (but unobserved) stronger attachment to the labour market which would also prompt earlier return than on average. Over and above these observed and unobserved population differences, having rights induces around $20 \%$ more women to return to their previous job before 7 months than would otherwise be the case. So in $1991 / 240 \%$ of women were back at work before their child was 8 months old and maternity rights legislation is partly responsible for this pattern of early return.

Section 2 presents the structure of legal rights in the UK and the current proposals for reform. Section 3 discusses the, mainly, US literature on the behaviour of women after birth. Section 4 lays out a simple theoretical model of how rights will affect behaviour. Section 5 lays our estimation strategy and how we can control for unobserved heterogeneity. Section 6 describes the data used and presents some basic information. Section 7 reports results estimates discrete choice hazard models with instrumental variables to identify the specific effect of rights on behaviour. Section 8 offers some conclusions. 


\section{The policy context}

The ALSPAC dataset surveyed mothers whose expected delivery date fell between $1^{\text {st }}$ April 1991 and $31^{\text {st }}$ December 1992 , so it is the policy regime in effect at this time with which we are concerned. The following highlights only the main points of maternity legislation (a more detailed treatment can be found in Appendix B).

The right to return: Mothers were entitled to return to their pre-birth job at any time up to 29 weeks after the birth provided that they had worked for the same employer for a minimum of 2 years full-time or 5 years part-time. They were also required to work at least until the $11^{\text {th }}$ week before their EWC (expected week of confinement).

Statutory Maternity Pay (SMP): SMP was payable for a maximum of 18 weeks.

Those women who fulfilled the conditions for the right to return (see above) received 6 weeks SMP at $90 \%$ of their previous salary, followed by 12 weeks paid at a flat rate. Women who did not meet these conditions but had been continuously employed by the same employer for 6 months received the basic flat rate payment for all 18 weeks.

Maternity Allowance (MA): MA was paid by the DSS, also for a maximum of 18 weeks, at a lower flat rate than SMP. MA covered some women who were unable to qualify for SMP, such as the self-employed and those who had changed employers.

Contractual Maternity Pay (CMP): CMP covers any arrangements beyond the statutory minimum made at the employer's discretion. Some employers relax 
the rules on who is eligible for rights, on the length of coverage or on the amount of benefits paid.

Currently the lengths of paid and unpaid leave are unchanged at 18 and 29 weeks respectively. However, the qualifying restrictions for both rights have been relaxed so that some women who were not eligible in the early nineties would be today. The government's proposals for reform, which are in the process of being enacted, are that the length of paid leave be extended to 26 weeks and that of unpaid leave to 52 weeks.

\section{Existing Literature}

This section briefly reviews the findings of some studies that have examined the relationships between the return to work decision, leave entitlements and other characteristics of the mother (in particular her pre-birth work status). The methodology of certain key papers is discussed more fully later.

Waldfogel and Berger (2001) provide a good summary of the literature on post-birth employment decisions, most of which is US-focused. There is some consensus that women who worked during pregnancy are more likely to work after birth and return more quickly than women who did not work during pregnancy (e.g. Smith, Downs and O'Connell, 2001). The higher the opportunity costs of withdrawal from the labour force, the less likely it is that a mother will stay at home. For example, higher education and higher wages are associated with an increased probability of return while other family income is negatively related to the probability of early return (Desai and Waite, 1991). 
With regard to the effects of maternity leave, there is evidence that leave policies do affect the return decisions of new mothers. Waldfogel (1999) finds that the passing of the 1993 Family and Medical Leave Act in the US (which guaranteed 12 weeks of job-protected maternity leave for qualifying women) led to increased leave-taking among the newly-covered. Ross (1998) is in accord with this finding and estimates that leave lengths for those who gained coverage rose significantly after the introduction of the act. Several papers (e.g. Waldfogel, 1998, Glass and Riley, 1998) find that mothers who worked in pregnancy are more likely to return to their pre-birth employer (rather than quit the labour force or take a new job) the greater the generosity of that employer's leave policy.

Whilst of general interest, most of this work does not directly address the effect of maternity rights on the duration until a mother returns to work. Waldfogel and Berger (2001) tackle this issue. In a similar spirit to this paper they estimate a hazard model of time until return in the US and find that women with leave coverage return sooner than those without coverage. They also find that mothers with leave coverage are more likely to take a leave of more than six weeks but less likely to take a leave of more than twelve weeks. The first result suggests that maternity rights are successful in allowing mothers to stay out longer than the maximum allowed for the period of disability following childbirth in the US. The second result suggests that the 12-week limit of the FMLA-mandated leave period causes women to bring forward their return in order to retain their pre-birth jobs.

Ondrich, Speiss, Yang and Wagner (1998) use data from the German SocioEconomic Panel to directly address the question of how extensions to the length of maternity leave affect behaviour. They postulate that the extension of the job protection period potentially has two distinct effects. The 'horizon' effect serves to delay a mother's return by allowing her stay out longer and retain her old job. The 
'replacement' effect relates to the fact that although the mother has the right to return to her old employer until the end of the protection period, the longer she stays out the more likely it is that she will be 'replaced' in her pre-birth job. As her human capital depreciates during her time at home, she may find that after a long leave she returns to a position that is inferior to her pre-birth working environment. Ondrich et al argue that after an extension this effect could lead to a fall in the end-of-leave cumulative return probability, essentially because of a decline in the opportunity cost of staying at home.

In order to test their predictions they estimate return to work hazards and utilise the fact that German federal law has increased the potential duration of maternity leave five times since 1985 . They find that an increase in potential duration of leave from a time limit of $T_{1}$ to $T_{2}$ leads to a decline in hazard rates prior to $T_{1}$ and an increase in hazard rates between $T_{1}$ and $T_{2}$. They interpret this as evidence that an increase in leave entitlements causes mothers to delay their return but that most will not take full advantage of the new leave period because of fears of 'replacement'. The exception to this seems to be women with high education and labour force experience. They are more likely to take their full leave entitlement and return to work at $T_{2}$ as soon as it expires.

The present paper uses the ALSPAC dataset to analyse the effects of maternity rights legislation in the UK. The key problem that arises in any attempt to measure the impact of a policy intervention concerns how one constructs the counterfactual what the outcome for an individual would have been if they had not been exposed to the intervention. Unlike Waldfogel and Berger (2001), for example, we are unable to exploit exogenous regime changes over time. We therefore apply several alternative 
techniques to minimise selection bias and so to capture the true effects of rights entitlements on behaviour.

\section{Theoretical framework}

Here we present a basic framework for thinking about how mothers' behaviour may change in response to the existence of maternity rights. The model has deliberately been kept as simple as possible in order to highlight the key effects of maternity rights and so abstracts from complications such as uncertainty and discounting.

Let $T$ be the time elapsed since the birth of the child (in months), $T_{P}$ is then defined as the date at which maternity payments expire, $T_{R}\left(>T_{P}\right)$ is the date at which the right to return to one's old job expires and $T_{F}$ is the end of the analysis period. The definition of the analysis period as finite serves to simplify the model considerably. The mother's decision problem is to choose $T^{*}$, the date at which she returns to work or, equivalently, the amount of time she is available full-time at home with the baby. ${ }^{1}$

We also assume for convenience that when a mother returns to work she remains in the same job until $T_{F}$ and that she receives the same wage throughout her employment. The wage at which a mother starts back depends on whether she returns to her old job or begins a new one. We assume that the wage in her old job, $w_{O}$, is strictly greater than the wage in a new job, $w_{N}$.

\footnotetext{
${ }^{1}$ Since all the discussion relates to a single individual we suppress individual sub-scripts here but note the wage fall on return to a new job and preferences will vary across individuals.
} 
We can think of this wage difference as reflecting the return to firm-specific human capital and is analogous to that found in the cost of job loss literature (see Farber, 1993, or Jacobsen, LaLonde and Sullivan, 1993). Gregg and Wadsworth (2000) show that men and women starting new jobs after a spell out of work receive wages well below others with the same characteristics. There is also more specific evidence that new mothers do in fact take a wage cut when they seek new employment after a birth (see for example, Waldfogel, 1998).

As the right to return expires at $T_{R}$ we can write the starting wage $w$ as a function of $T^{*}$. If a mother returns by $T_{R}$ her wage throughout employment is $w_{O}$; if she returns after $T_{R}$ her wage is $w_{N}$.

$$
\begin{gathered}
w\left(T^{*}\right)=w_{O} \text { if } 0 \leq T^{*} \leq T_{R} \\
=w_{N} \text { if } T^{*}>T_{R}
\end{gathered}
$$

Maternity pay is paid at rate $m$ per period which for simplicity we assume is a constant fraction, $\alpha$, of the pre-birth wage. Maternity pay is received in every period from birth until it expires, or the mother returns to work, whichever happens first.

$$
\begin{aligned}
m \quad & =\alpha w_{O} \text { for } 0 \leq T \leq \min \left(T^{*}, T_{P}\right) \quad \alpha<1 \\
& =0 \text { otherwise }
\end{aligned}
$$

Mothers are also able to rely on other family income which is received at a constant rate $y$ per period.

Because the changes in wages and maternity pay are essentially binary, it is simplest to analyse this model in a static framework that converts rates of income flow into total income received between 0 and $T_{F}$. To this end we define $W$ as the total 
earnings from employment which, ignoring discounting, is simply the starting wage defined in (1) multiplied by the number of periods for which it is received: $W\left(T^{*}\right)=w\left(T^{*}\right) \cdot\left(T_{F}-T^{*}\right)$. We can calculate total income from maternity pay, $M$, and total income from other sources, $Y$, in a similar way: $M\left(T^{*}\right)=m \cdot \min \left(T^{*}, T_{P}\right)$ and $Y=y \cdot T_{F}$. Finally, we can define total income from all sources between 0 and $T_{F}, I$, as the sum of these three elements.

$I\left(T^{*}\right)=W\left(T^{*}\right)+M\left(T^{*}\right)+Y$

Mothers also derive utility from income and from time spent with the baby. The mothers' utility function will also incorporate heterogeneity of tastes for income and time preferences. The decision problem is to choose $T^{*}$ to maximise the utility she receives from the two sources.

$$
\max _{T^{*}} U=U\left[I\left(T^{*}\right), T^{*}\right]
$$

We assume positive marginal utility of income and positive but diminishing marginal utility of time spent at home with the baby.

$$
\begin{aligned}
& \frac{\partial U}{\partial I\left(T^{*}\right)}>0 \\
& \frac{\partial U}{\partial T^{*}}>0 \text { and } \frac{\partial^{2} U}{\partial T^{2}}<0
\end{aligned}
$$

Given this utility function we can derive indifference curves with a slope given by the marginal rate of substitution.

Our question of interest is how the optimal value of $T^{*}$ varies with changes in $T_{P}$ and $T_{R}$. We can illustrate graphically how our assumptions about the wage and maternity pay combine to form different budget constraints or opportunity sets. The 
indifference curves in our model have the standard form and it is the opportunity set facing the mother that generates the interesting features of our model.

\section{Figure 1}

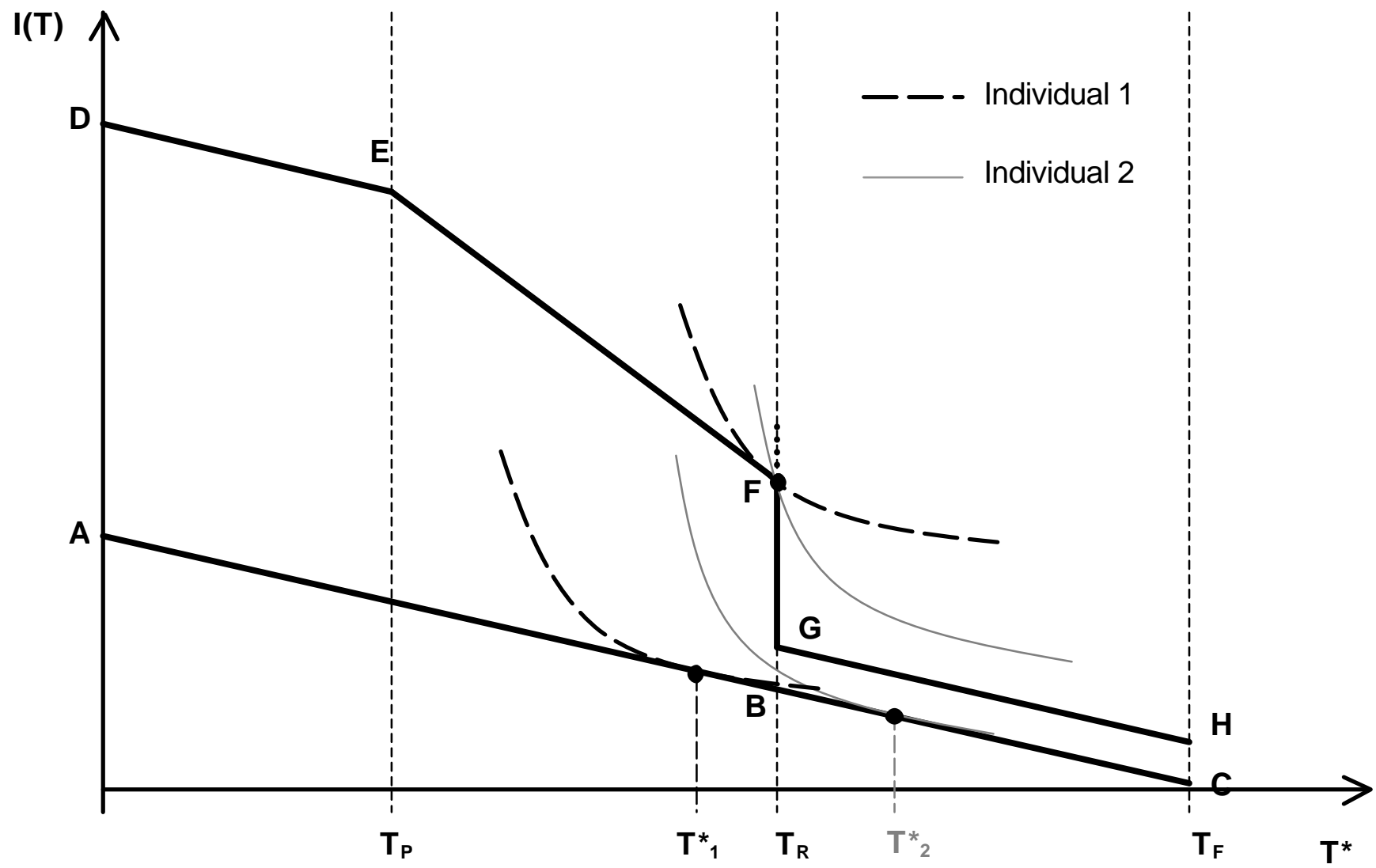

Figure 1 shows how the opportunity set for an individual changes with the introduction of maternity rights. With no maternity pay and no right of return an individual would face the opportunity set $A B C$, the slope of which is simply $-w_{N}$. Introducing the right to return, which expires at $T_{R}$, and maternity pay, which expires at $T_{P}$, yields an opportunity set of DEFGH. The kink point at $\mathrm{E}$ is caused by the fact that the withdrawal of maternity pay if a mother returns at any time before $T_{P}$ imposes an effective tax rate of $\alpha$ on earnings in this period. For all return dates after $T_{P}$, the introduction of maternity pay has a pure income effect equal to the distance HC. The steeply sloped section EF reflects the fact that if a mother returns before $T_{R}$ she works at the higher wage $w_{O}$ and therefore the cost of remaining at 
home another month is higher. However, if she returns after $T_{R}$ her total earnings fall to $w_{N}\left(T_{F}-T^{*}\right)$, hence the discontinuity at FG.

How might the imposition of maternity rights affect behaviour? Figure 1 illustrates just 2 of the many possible cases. In the absence of rights, Individual 1 would choose to return at $T *_{1}$. When the opportunity set shifts to $\mathrm{DEFGH}$, she increases the amount of time spent at home with the baby to $T_{R}$. Thus this individual delays her return for as long as possible without losing the right to return to her old job. The effect of introducing maternity rights for Individual 2 is to decrease the amount of time spent at home with the baby. This mother has relatively strong tastes for time at home compared to income and would return at $T^{*}$ in the absence of rights. With rights however, her return time falls to $T_{R}$. It is optimal for her to sacrifice some of the time spent at home in exchange for the higher income from returning to her pre-birth job.

It is worth noting that although both individuals would return at the same time, $T_{R}$, were they eligible for rights, the indifference curve of neither is tangent to the opportunity set at the optimal $T^{*}$. The discontinuities in the opportunity set lead to the well known result that individuals with non-identical preferences may choose exactly the same allocation. We would thus expect to observe clustering at the kink points $E$ and $F$ which is in fact exactly what we do observe in the data (see Section $6)$.

This framework helps to give some predictions as to the effects of various characteristics on return times. We would expect that lower income from other sources [Y] would lead mothers to value income relatively highly compared to time with the baby, and thus be on a flatter potion of the indifference curve and to tend to 
return earlier. The larger the wage gap $w_{O}-w_{N}$, the greater the discontinuity at FG. If this cost of separation reflects loss of firm specific human capital then those with longer tenures will return earlier. If in addition there is a loss of returns to human capital (as found by Gregg and Wadsworth, 2000, for all people returning to work after a separation) then this will especially affect the better educated. Again, this may make mothers more likely to get caught at the corner point $F$ as there is a stronger incentive to retain one's old job. In general, the higher the wage, the greater the opportunity cost of time spent at home. On the other side, factors which raise the utility of time spent with the baby will tend to increase return times, for example if the baby were unwell.

\section{Estimation Strategy}

\section{$\underline{5.1}$ The selection problem}

Our estimation strategy is to produce estimates of when mothers with maternity rights would have returned if they had not had maternity rights or pay. This should enable us to see which mothers' behaviour was shifted and by how much their preferred return time changed. In terms of Figure 1, we know mothers' optimal $T * \mathrm{~s}$ for the opportunity set DFGHI and we wish to predict what the optimal $T * \mathrm{~s}$ would have been if mothers had faced the opportunity set $A B C$. We can then examine which characteristics, such as education and social class, are associated with shifts of different magnitudes and direction.

The standard starting point is to predict a return time for mothers with rights on the basis of the behaviour of those without rights. There is a selection problem here, however, that will result in biased estimates of the counterfactual return time. 
Mothers with maternity rights are those women who satisfied the qualifying conditions in terms of their previous employment experience. They will thus have been employed by the same employer for a considerable period of time and will have remained in their jobs well into their pregnancies. The variable indicating maternity rights status will be correlated with unobservables such as tastes for work that will be negatively correlated with return times. The maternity rights variable is thus endogenous and if we predict the behaviour of mothers with rights on the basis of those without rights we will tend to overestimate the length of time they would have spent at home.

Several methods have been used to deal with this problem in the literature on maternal employment. Desai and Waite (1991) estimate hazard models of the mother's return to work decision although they make no attempt to estimate the effects of maternity entitlements. They recognise that unobserved heterogeneity amongst the women in their sample exists along a dimension they call 'work commitment'. Their solution is to control for long-run preferences by including a variable of the response to the question 'What would you like to be doing when you are 35 years old?'. They classify women who want to be working at 35 as having 'high work commitment' and those who would prefer to be at home or engaged in some other activity as having 'low work commitment'.

In a similar spirit, we include as a control an attitudinal variable that helps to 'net out' the unobserved factors that are correlated with rights status. The variable we use is the response to the question 'What is the youngest age at which you think it is alright for a mother to leave her child regularly in the care of another person during the day?'. This was asked at 32 weeks gestation. We argue that the response to this question reflects attitudes towards work and child-rearing that at least partly capture the degree of the mother's work orientation. Mothers with maternity rights are more 
likely to believe that children can be left in another's care at a younger age (see Section 6), as we would expect. Thus including this variable as a control mitigates the downward bias in the counterfactual hazard caused by the omission of labour market commitment.

However, only if our attitudinal variable fully captures the heterogeneity in unobserved work commitment will our results be unbiased. As it is unlikely that one variable can fully reflect all the unobserved differences between women with rights and those without rights, we explore two further methods of correcting for endogeneity bias.

First we explore the technique of sample selection also used by Waldfogel and Berger (2001). They take as a sample only those women who worked in the last trimester of pregnancy and, in some specifications, only those who also returned to work in the first year following the birth. The assumption is that the unobservable factors will be common to all women with this degree of labour market commitment. We follow this method of limiting our sample by discarding all the observations for women who did not work at all during their pregnancies. We argue that these women can be classified as having 'weak' labour market commitment and so do not provide a good comparison group for mothers with rights whose labour market commitment is 'strong'. To test the sensitivity of our results to this assumption we compare them with the results from the alternative method of just controlling for endogeneity bias.

Second, a standard strategy for overcoming the endogeneity problem is the instrumental variables (IV) approach. This method serves to 'cleanse' the maternity rights variable of the components that are correlated with both it and return time. Hujer, Maurer and Wellner (1997) use this technique within a hazard model to examine the effect of vocational training on the duration of unemployment spells in 
West Germany. Their problem is analogous to ours in that it is likely that there are unobserved factors correlated with both training participation and unemployment duration. Following Hujer et al we propose the probability to be entitled to maternity rights, which we estimate using a probit model, as a suitable variable. We discuss the instrument set when we use this technique in the next section.

\section{$\underline{5.2 \text { Methodology }}$}

The essence of our strategy is to estimate hazard models of time until return to work after a birth for mothers with maternity entitlements and for those without entitlements. Taking the observed characteristics of mothers with rights, we can apply the estimated coefficients from the first model estimated on the full sample to obtain a predicted hazard of when they actually returned. We can then apply the coefficients from the second model to the same sample to obtain predicted hazards of how this group of women would have behaved if they had not had rights. The difference between the two predictions gives us the effect of maternity rights on behaviour at each month of duration in the sample period.

This section first outlines our basic econometric model. We then go on to detail the extensions to the basic model that are needed to control for unobserved heterogeneity and endogeneity bias.

The estimation model we use is a discrete time version of the Cox Proportional Hazard model (see Narendranathan and Stewart, 1993, for example). The Cox model assumes that the hazard of return to work after the birth is of the form $\lambda_{i}(t)=\lambda_{0}(t) \cdot \exp \left(X_{i}(t)^{\prime} \beta\right)$ 
where $\lambda_{0}(t)$ is the baseline hazard at time $t, X_{i}(t)$ is a vector of (potentially timevarying) explanatory variables for individual $i$ and $\beta$ is a vector of parameters to be estimated. The associated continuous time survivor function is

$$
S\left(t ; X_{i}\right)=\exp \left[-\int_{0}^{t} \lambda_{i}(\tau) d \tau\right]=\exp \left[-\int_{0}^{t} \lambda_{0}(\tau) \cdot \exp \left(X_{i}(\tau)^{\prime} \beta\right)\right]
$$

If durations are only observed as whole months completed (as in our data) then an observed duration of $t$ whole months indicates a duration in continuous time of between $t$ and $t+1$ months. The probability of exit in the $t$ th month for person $i$ is $\operatorname{Pr}(t \leq T<t+1)=S\left(t ; X_{i}(t)\right)-S\left(t+1 ; X_{i}(t+1)\right)$

and the survivor function at the start of the $t$ th month is

$$
\operatorname{Pr}(T \geq t)=S\left(t ; X_{i}(t)\right)
$$

The hazard of exit in month $t$ is thus given by

$$
h_{i}(t)=\operatorname{Pr}(t \leq T<t+1 \mid T \geq t)=\frac{S\left(t ; X_{i}(t)\right)-S\left(t+1 ; X_{i}(t+1)\right)}{S\left(t ; X_{i}(t)\right)}=1-\left[S\left(t+1 ; X_{i}(t+1)\right) / S\left(t ; X_{i}(t)\right)\right]
$$

If we assume that the covariates $X_{i}$ are constant within each interval then we can write the hazard function as

$$
h_{i}(t)=1-\exp \left[-\exp \left(X_{i}(t)^{\prime} \beta+\gamma(t)\right)\right]
$$

where $\gamma(t)=\log \int_{t}^{t+1} \lambda_{0}(\tau) d \tau$. This specification allows us to estimate $\gamma(t)$ as a fully non-parametric baseline hazard with a separate parameter for each duration interval (in our case each month).

In this paper we estimate a generalised form of the discrete time hazard where the coefficients on several of the explanatory variables are allowed to vary over the duration of time spent at home. In the case of the rights variable, for example, this 
enables us to capture the idea that maternity rights should have a strong effect on the hazard prior to their expiry dates but less effect at longer durations.

We can write the discrete time hazard in this case as

$h_{i}(t)=1-\exp \left[-\exp \left(X_{i}(t)^{\prime} \beta+Z_{i}(t)^{\prime} \gamma(t)\right)\right]$

The variables are divided into two groups: those whose coefficients remain constant (the $X$ vector) and those which take a different coefficient in each month (the $Z$ vector). In the basic model the $Z$ vector contains only a constant [a dummy for with rights] and the $X$ vector contains all the variables. In the extended model the $Z$ vector also contains maternity rights status and potentially other covariates as well.

In fact, we would like to allow for the possibility that the effect of all the explanatory variables on return time, not just the time profile of the baseline hazard, varies with rights status. Thus we interact all the covariates with rights status or, equivalently, we estimate separate models for each sub-sample according to their rights entitlement. If $k=1,2$ indexes women with rights and women without rights respectively then we estimate two hazards of the form:

$h_{k i}(t)=1-\exp \left[-\exp \left(X_{k i}(t)^{\prime} \beta_{k}+Z_{k i}(t)^{\prime} \gamma_{k}(t)\right)\right]$

Our Z vector contains mother's social class and partner's employment status 8 weeks after the birth in addition to the constant. (We do not interact class and partner's employment with every month, however, but allow their coefficients to vary over 3 separate periods within the 34 months observation period.) Social class based on occupational classifications is a broad proxy for the wage (the opportunity cost of remaining at home) and partner's employment is a proxy for other household income. Their inclusion allows for the fact that the effect of maternity rights on behaviour at different points in time (particularly at the expiry dates) may vary with the mother's 
characteristics. For example, mothers with little other household income are more likely to be affected by the expiry of paid leave than the better off.

We estimate the discrete time hazard using a complementary log-log model in which we regard each exit or continuation in each month as an observation. First we define $c_{i}$ as an indicator variable equal to 1 if the mother returns to work within the observation period (34 months after the birth in our case) and equal to zero if her duration is censored. The $i$ th individual contributes $d_{i}$ observations to the sample where $d_{i}$ is her observed duration (completed or censored) in months. We then define a set if indicator variables $y_{i t}=1$ if individual $i$ has a completed duration of $t$ whole months and $=0$ otherwise. Thus

$$
\begin{aligned}
y_{i t} & =1 \text { if } d_{i}=t \text { and } c_{i}=1 \\
& =0 \text { otherwise }
\end{aligned}
$$

So if a mother does not return by the end of the observation period (i.e. $c_{i}=0$ ), $y_{i t}=0$ for all $t$.

The log-likelihood for mothers in the kth category of rights status can then be written in sequential binary response form as:

$$
\ln L_{k}=\sum_{i=1}^{n_{k}} \sum_{t=1}^{d_{i}}\left\{y_{k i t} \cdot \ln h_{k i}(t)+\left(1-y_{k i t}\right) \ln \left(1-h_{k i}(t)\right)\right\}
$$

\subsubsection{The instrumental variables technique}

Earlier in this section we outlined three alternative methods for tackling the problem of the endogeneity of the maternity rights variable. We first present results in which the only attempt to control for endogeneity is the inclusion of our attitudinal variable. 
The second approach is to restrict the without rights category to those who worked during the pregnancy which is pre-condition for having rights. This makes the comparison group more like those with entitlements in that they have a recent period of employment and are thus likely to have stronger labour market attachment. But as the reasons people worked and not had rights might not be exogenous (because they have chosen to work part-time in the past, for instance) we also present results in which rights status is instrumented.

Using the IV technique, we substitute actual entitlement to maternity rights with the probability of entitlement, a variable we argue will be correlated with actual entitlement but not with return time. We estimate these probabilities using the following probit model:

$q_{i}^{*}=W_{i}^{\prime} \alpha+\varepsilon_{i}$

$q_{i}=1$ if $q_{i}^{*}>0$

$q_{i}=0$ otherwise

$q_{i}{ }^{*}$ is the propensity to be entitled to maternity rights and is not observed. $q_{i}$ is actual entitlement. The vector $W_{i}$ contains all the explanatory variables from the hazard model ( $X_{i}$ and $Z_{i}$ ) plus a set of instruments that provide some exogenous variation in whether women who worked in pregnancy qualified for maternity rights or not. The estimated probability for individual $i$ to be entitled to maternity rights is $\Phi\left(W_{i}^{\prime} \hat{\alpha}\right)$ and it is this variable we use to replace actual rights status in the hazard model.

5.2.2 Analysing the effect of maternity rights on behaviour 
Having estimated the various models in the ways outlined above, how can we use our results to say something about the effects of maternity rights? Although we have used a hazard model to derive our results, it turns out that it is most convenient for interpretation if we present the estimated distribution rather than the hazard. The question of interest is how mothers adapt their return time (either forwards or backwards) in response to rights entitlement. We are therefore less interested in the probability of return in a particular month given no return up to that point than in the probability of return in a particular month overall. Recall from equation (11) that $h_{i}(t)=\frac{\operatorname{Pr}(t \leq T<t+1)}{\operatorname{Pr}(T \geq t)}$. The probability distribution can thus be derived from the hazard:

$\operatorname{Pr}(t \leq T<t+1)=p_{i}(t)=h_{i}(t) \cdot \operatorname{Pr}(T \geq t)=h_{i}(t) \cdot\left[1-\sum_{s=0}^{s=t-1} \operatorname{Pr}(s \leq T<s+1)\right]$

Our method is to compare the distributions derived from the following estimated hazards:

$\hat{h}_{1 i}(t)=1-\exp \left[-\exp \left(X_{1 i}(t)^{\prime} \hat{\beta}_{1}+Z_{1 i}(t)^{\prime} \hat{\gamma}_{1}(t)\right)\right]$

and

$\hat{h} c_{1 i}(t)=1-\exp \left[-\exp \left(X_{1 i}(t)^{\prime} \hat{\beta}_{2}+Z_{1 i}(t) \hat{\gamma}_{2}(t)\right)\right]$

$\hat{h}_{1 i}(t)$ is the predicted hazard for when a women with maternity rights $(k=1)$ actually returned as it uses the estimated coefficients for the sample 'with rights' ( $\hat{\beta_{1}}$ and $\left.\hat{\gamma}_{1}(t)\right) \cdot \hat{h} c_{1 i}(t)$ is the counterfactual predicted hazard for when a woman with rights would have returned if she had not had rights - it uses the estimated coefficients for the sample who worked in pregnancy but did not have rights $\left(\hat{\beta_{2}}\right.$ and $\left.\hat{\gamma}_{2}(t)\right)$. 
Of course, in the IV model the rights variable is continuous rather than binary so we can no longer estimate a separate hazard model for each rights category. Instead we estimate one model in which the probability is interacted with all the other covariates. We can then construct the actual and counterfactual return probability distributions by assigning different values to the probability (one low and one high) and calculating the overall predicted probability of return at each month of duration.

\section{The data}

The data we use come from the Avon Longitudinal Study of Parent and Children (ALSPAC) which surveyed 14000 pregnancies in the Avon area in 1991 and 1992. Contacting mothers was undertaken through medical agencies, so that this is not a national sample of births but effectively a localised census. The sample contains details of 12,007 births with at least some post-birth data. This lower number reflects late miscarriages, still births and refusal to participate post-birth. This latter attrition is not random and is disproportionately among lone and less educated mothers. Our working sample size is somewhat smaller than this as a result of selecting only those who report information on return dates (1882 missing observations) and whether they worked during the last trimester of pregnancy (which defines maternity rights). The main sample is thus 9582 observations.

Our observation period for the duration of time spent at home is censored at 34 months after the birth. Between the start of the study and this date mothers answered 8 questionnaires on their own circumstances, 4 of which were administered prior to the birth. They also answered a further 6 questionnaires after the birth related directly to their children. Data on the actual month of return is available only up until the 34 month questionnaire. Beyond that, we know if a mother returned between 34 and 47 months but not the exact date of return. Although the ALSPAC dataset is extremely 
rich, its main focus is on the health and development of children and it does have limitations from an economic point of view. The following section sets out how we have generated our key variables from the information available.

\section{$\underline{6.1 \text { Return times }}$}

The dependent variable in all our analysis is the age of the study child in months when the mother started work after the birth. The 29-week cut-off for the right to return, then, falls in the $7^{\text {th }}$ month after the birth. With regard to maternity pay, the situation is complicated by the fact that mothers are able to begin their paid leave period a number of weeks prior to the birth. Thus the $18^{\text {th }}$ week after the birth (or the $4^{\text {th }}$ month in our framework) represents the maximum date for the receipt of statutory maternity pay. If, as anecdotal evidence suggests, most mothers start their paid leave just prior to the delivery date, then the $18^{\text {th }}$ week will actually fall in the $3^{\text {rd }}$ month. So we would expect the expiry of maternity pay to range over several months, particularly when employers' arrangements beyond the statutory minimum are taken into account.

We have no information on whether a mother returned to her pre-birth job or began a new job. We also make no attempt to take account of her subsequent employment behaviour after the return nor whether she worked full or part time on return. We do observe, however, whether she was working during the pregnancy.

\section{$\underline{6.2 \text { Maternity rights and labour market commitment }}$}

Although we do have data on pre-birth employment, we do not know whether a mother actually qualified for maternity rights. As a proxy, we define a mother as having maternity rights if she worked in the $28^{\text {th }}$ week of her pregnancy or later. 
Those who stop working prior to this date even for medical reasons will lose the right to return to the same employer post-birth. So those classified as not having rights can be split into two sub-groups - those who worked in pregnancy but stopped before 28 weeks (in what follows we title these as having "some attachment" to the labour market) and those who did not (weak attachment). The latter group is discarded from the sample when we focus our analysis on the women with the strongest labour market attachment (see Section 5). Other missing variables are wages, both pre- and post-birth, and other family income.

\subsection{Overview of the data}

The question we are asking is whether employment rights induce mothers to return to work earlier than would be the case in their absence. Our model suggests that the utility from income is traded off against utility from caring for the child in these early months. Maternity rights encourage early return by protecting the wages in the prebirth job which are higher than those that can be obtained in a new post but only on condition of return by 7 months. Table 1 shows these issues from the mothers perspective; mothers hold a wide range of views about when they feel it is alright for a child to be left in the care of other adults. Some $28 \%$ of the sample think this can be as early as 6 months, whilst $29 \%$ think that this is not true until the child is aged over 36 months. Those mothers with employment rights disproportionately make up the population of mothers who feel it is alright to leave the child when very young but, even so, women with employment rights are frequently returning to work before they feel comfortable about doing so. So, in Table 1, 22\% of women with rights who feel a child should be at least a year old before being left in the care of others are back at work by the end of the 4 th month and another $15 \%$ are back by the $7^{\text {th }}$ month. Those without employment rights with the same beliefs return much less frequently in these 
early time windows. So it appears that a lot of women are concerned about a trade off between protecting their employment position and their child's welfare.

Before going on to examine the explanatory variables in detail, we can take a quick overview of the data to get an idea of the patterns in return times. Table 2 describes the population of study and when mothers returned across the sub-groups discussed above. Some $63 \%$ of mothers fall into our "with rights" category where they worked late into their pregnancy, whilst $9 \%$ worked during the pregnancy but stopped working prior to 28 weeks (some attachment). The first striking thing about return patterns is how many women are back at work very early after the birth. Some $23 \%$ of all mothers are back at work by the end of the $4^{\text {th }}$ month, or when paid leave ends. By the end of the $7^{\text {th }}$ month some $40 \%$ of mothers have returned. For those with maternity rights however, nearly one third are back by 4 and nearly $55 \%$ by 7 months. By contrast around a third of all mothers have not returned by the end of the $34^{\text {th }}$ month; just $19 \%$ of those with rights and over $60 \%$ of those who did not work during the pregnancy. Figure 2 a shows the unconditional monthly distributions of return times for mothers with rights and for mothers without rights. The large spikes at 3 and 6 months in the distribution of those with rights are immediately noticeable. Given the timing and the fact that we do not observe comparable spikes for those without rights, it is plausible that this clustering is the result of maternity legislation, as predicted by our theoretical model. Figure $2 \mathrm{~b}$ makes this clear by reporting the differences in return rates across those with and without rights. It is also noticeable that there are smaller spikes in the data at 12, 18, 24 and 30 months. We argue that although this may be partly due to rounding errors in the reporting of return times, it is also likely to reflect rounding in behaviour in that mothers may make long-term plans to return 'after a year', 'after a year and a half', etc. 
Figure $3 a$ groups the data in Figure $2 b$ into 6 time windows so that it is easier to see the timing of events. In this raw data the return among those with rights is markedly higher right through to 7 months. Some 6 percent more mothers with rights are back at work before the child is 3 months old and another 17 percent at the 3-4 months spike. Another $19 \%$ more mothers with rights are back by the $7^{\text {th }}$ month. Those without rights are slightly more likely to return between 12 and 34 months but the big gap is in not having returned at all by the $35^{\text {th }}$ month. So these populations have a very large behavioural difference with a swing of just under $40 \%$ of the population shifting between returning by 7 months (with rights) or staying out to beyond 34 months (without rights).

The lower panels of Table 2 and Figures $3 b$ and $3 c$ highlight how these differences in patterns of return vary across dimensions of the population which are likely to influence outside income sources and the value of the mother's wage on return. Mothers with rights in lower class occupations are relatively more likely to return during the paid maternity leave period (up to 4 months) and less likely to return during the unpaid leave period compared to higher paying occupations. Likewise those with non-working partners and maternity rights are the most likely to return by the end of the $7^{\text {th }}$ month and especially by the end of the paid leave period. So those with the greatest reliance on the mother's income return earliest whereas professional/managerial women with working partners make most use of the maximum unpaid leave period.

\section{$\underline{6.4}$ Other independent variables}

Of course, the inferences made above assume that the distribution of return times of those without rights accurately reflects how the women with rights would have behaved in the absence of their entitlements. No attempt is made to control for 
differences in the composition of the two samples - either on observable factors or unobservable factors. This, then, is the role of the duration analysis. We can include a wide range of other controls (the full list of the independent variables and their means is given in Appendix Tables A1 and A2) but our theoretical model suggests that we should narrow our focus to certain key variables. The mother's education, social class and age all provide proxies for the opportunity costs of remaining at home with the baby. Variables capturing the partner's employment, education and social class provide information on the other financial resources available to the household. And variables relating to the health of the mother and baby, and to attitudes, should help to control for constraints and to some extent unobservable 'tastes' for staying at home with the baby. As the set of the explanatory variables is very large and many are likely to be highly correlated, we discuss the impact of introducing controls in groups. In addition to basic controls, such as the mother's age at birth, the ethnicity and the sex of the baby, we have four groups of variables; the mothers social and financial capital, household composition, health information on the mother and the child, and our set of instruments which are discussed later.

\subsubsection{The mother's social and financial capital}

This covers her highest educational qualification, her social class (which is derived from information about her last known occupation). Whether she worked full time, part time or casually in her last employment gives further information on the likely opportunity costs of remaining at home. The household's home ownership status is also included as an indicator of household wealth. Three variables relating to the mother's childhood and family background serve to capture other less tangible aspects of her social capital. Finally, we include a measure of 'disruption' to the mother's life in the 8 months after the birth. This weighted life event score is calculated by asking the mother whether 40 'life events' (such as an illness, the loss 
of a job, divorce, etc) occurred in the relevant period and if so, how strongly they affected the mother. The total score is the sum of the number of events that occurred, weighted by their reported effect on the mother. This measure helps to control for shocks that may affect the mother's ability or desire to return to work.

\subsubsection{Household composition}

We include a set of variables to control for the composition of the household during pregnancy, e.g. numbers of siblings and the gap since the previous birth and for subsequent pregnancies after the birth of the study child. For the purposes of the duration analysis we introduce a time-varying covariate - a dummy variable that takes the value of 1 in every month from the conception of the first child after the birth of the study child to the end of the observation period. This ensures that subsequent pregnancies do not affect the hazard of return before they occur. For mothers where the date of conception is missing we simply include a dummy variable that equals 1 in all months if she had at least one pregnancy. A separate dummy captures any further pregnancies during the observation period. Information about the partner (if one exists) also falls into this category. We include partner's residence status and their employment status 8 weeks after the birth and also education and social class to proxy the partner's wage. Partner's health prior to the birth is also included as this may help reflect the importance of the mother's earnings to the household.

\subsubsection{Health and pregnancy related variables}

This section covers various factors that might affect the mother's preferences for time spent with the baby. We include measures of the mother's physical and mental health at 8 months after the birth and a variable capturing whether or not the pregnancy was intentional. From the time of the birth we looked at measures of the 
strongest analgesia used in labour, whether the baby had a low birth weight and whether the baby was admitted to a special care unit but none of these proved important in the return to work timing. The attitudinal variable discussed in the introduction and more substantially in Section 5 on the youngest age the mother thinks her child may be left in another's care also falls into this section.

\section{Results}

\section{$\underline{7.1 \text { Conditioning on characteristics and stated preferences }}$}

First we report results from separate discrete hazard models for those with and without rights. The very large number of individual coefficients means that we report the most important results via figures showing time variation in patterns of return (full estimation results are given in Appendix Table A3). The figures show the predictions of what mothers with rights would have done on the basis of the two equations. Here we discuss the general pattern of results across the major groupings discussed earlier. Among women without employment rights, older women are less likely to return to work quickly, as are less educated mothers without rights. Those with no partner or a non-working one are also less likely to return quickly. Those that worked part-time in their last job do return earlier than those that worked full-time. This probably proxies that the person worked more recently, as part-timers needed longer periods of work to gain rights in 1991/2. The numbers of adults and older siblings in the household made no difference to return timings for those without rights. The reported health of the mother and child post-birth are not important either. Further births over the time window observed reduced the likelihood of return to work. Having a partner who was in a professional or managerial job extended the period before a mother returned to work. The final point of note is that those women who report that 
they believe that it is not alright not leave the child in the care of another adult before that child reaches a year are substantially less likely to return to work early. This captures to some degree the mother's attitudes to parenting. Over and above the main focus of our results to be discussed shortly there are some other differences in patterns of return among those with maternity rights. Older women are not less likely to return to work quickly and part-time workers in last job are not more likely to return early. Women who have rights and have had a previous birth are more likely to come back quickly than those without rights (probably reflecting a previous choice). The distribution of the attitudinal variable is of interest as it is consistent with our hypothesis that it proxies unobserved attitudes towards work and child-rearing.

The main story is, however, contained in the Figures 4 and 5. Here we report the differences between the predicted return times for mothers with rights from the models estimated on those with and without rights. So we are looking at what women with rights did compared to what a woman with equivalent observable characteristics did without rights. The differences here then are corrected for having different characteristics and only reflect different propensities to return for given observed characteristics. Figure $4 a$ thus repeats $2 a$ but the lower line is now reflects what those with rights would have done in their absence. The main point of this is how similar the picture in Figures $4 \mathrm{a}$ and $4 \mathrm{~b}$ are when compared to Figure $2 \mathrm{a}$ and $2 \mathrm{~b}$. Controlling for observable heterogeneity thus leaves the difference rights make to the pattern of return times broadly unchanged. Figure 5a-c confirms this unchanged picture applies to the differences in the heights of the two spikes across occupation groups and whether there is a working partner or not. 


\section{$\underline{7.2 \text { Selection of those working during pregnancy }}$}

Having worked immediately prior and into the pregnancy is a pre-requisite of having maternity rights. This required labour market attachment is likely to contain information about the mothers not captured by other observable characteristics. But there are many who have worked but are not entitled to these rights. These working without rights contain a mixture of part-timers who have to work far longer to achieve maternity rights and those who for a variety of reason do not continue to work through to 11 weeks prior to the expected due date. Some of this latter group are likely to have stopped work for medical or other reasons. These can be thought of being weakly exogenous to the individual's underlying labour market attachment and form the basis of our instrument set. This group who have recent employment histories but no rights form a more natural comparator group than mothers who have no recent work history. So we next explore how this group's return patterns compare with the main with-rights group. As for all mothers without rights, older women who have recently worked but do not have rights are less likely to return to work quickly, and younger (under 20) mothers return more quickly than prime age mothers or the same age groups with rights. Those mothers without rights who have no partner or one who is not resident in the same household are less likely to return to work than the same groups with rights. But the main differences in return patterns are described in Figures 6a,b and 7a-c. The 'worked during pregnancy but without rights' group return to work earlier that those with no recent past employment history. Hence in Figure 6a the comparator line to the with rights group is now higher than for the full sample. There are still no spikes at 3 and 6 months but there is a clearer sense that there are more mothers without rights returning to work from 8 to 34 months than among those with rights. In other words there is a stronger picture that having rights is drawing women, who would have returned by the time their child reached age 3 
but after 7 months, to return at the 3 and 6 month spike points. The sense that these two spikes are made up of different groups remains, with the first spike consisting more of lower waged occupations and those with non-working partners and the second of professional and managerial women with working partners.

\section{$\underline{7.3 \text { Instrumental Variables }}$}

Despite the fact that observable differences between mothers with and without rights explain little of the differences in return times it is likely that having rights reflects a greater attachment to the workforce as well as the legal entitlements. Hence we use an instrumental variables approach to capture this unobserved component (see equation 17). Our instruments are designed to capture reasons why someone may not stay in employment through to the third trimester (which prevents rights entitlement) for reasons that are exogenous to the mothers' attachment to the labour force. These fall into three broad groupings:

\subsubsection{Residence and life events in pregnancy}

These variables include whether the mother had lived in the Avon area for less than a year, whether she moved house during her pregnancy and if so, whether her partner simultaneously started a new job. The rationale is that changes in location due to her partner's employment provide a weakly exogenous reason for mothers to leave their employment before they qualify for maternity rights. In a related vein we use a weighted life events score (see above) for the period of pregnancy. The accumulation of disruptive events in the mother's life provides another potential source of exogenous variation in whether she qualifies for maternity rights. Note that we have a similar measure post-birth included to capture whether the mother generally has a more chaotic life. So the idea is that by chance a number of events 
have happened to the mother making completion of the pregnancy whilst at work more difficult.

\subsubsection{Work related variables}

It is likely that the characteristics of a mother's pre-birth job influence her decision of whether to remain in her job long enough to qualify for maternity rights. We include variables related to whether her workplace was noisy or smoky, whether she was exposed to chemicals or fumes in her job and her usual mode of travel to and from work.

\subsubsection{Pregnancy and Health during pregnancy}

This section relates to events that may happen in pregnancy that cause the mother to fear for the welfare of the unborn baby, for example if she had a miscarriage scare. Such events might lead mothers to be particularly protective of their physical health and so perhaps to leave work before qualifying for maternity rights. In a similar spirit we include variables that deal with problems in previous pregnancies that may make the mother particularly cautious. Examples are whether she had previously had a miscarriage or a premature baby. In our data, there are a large number of pregnancyrelated physical and mental health measures during pregnancy. We pay particularly attention to pregnancy-related ailments such as morning sickness, hypertension and diabetes as these illnesses should have no impact on behaviour after the birth. Longer-term health considerations will influence behaviour both before and after the birth and so will not fulfil the conditions necessary for a valid instrument.

Table 3 is a table of the means and standard deviations of the instruments. All our explanatory variables are categorical. Hence the means given in Table 3 are the 
proportion of the sample (who answered that question) that fall into each category. Data on one or more characteristics are missing for some respondents. To avoid excluding these women, dummy variables denoting the presence of missing values for each characteristic are included in the estimation model.

It is clear from Table 3 that those who worked during pregnancy with and without rights differ substantially across our instruments. Those who stop working during the pregnancy are more likely to have moved to the area, moved house coincident with partner starting a new job and have had far more life event shocks occurring during the pregnancy period. They more often worked in noisy, smoke and fume filled environments and are far less likely to travel to work by car. They also report more past miscarriages or low weight births and far more health problems during the pregnancy, including being hospitalised. The table also reports F-tests for the instruments which suggests they are strong predictors of having rights.

Figures $8 a-b$ and $9 a-c$ report the same information as before but now use a comparison of predictions on the basis of having a low predicted probability of having rights (equivalent to the mean in the 'no rights' group) and a high one (equivalent to the predicted propensity in the 'with rights' group). This instrumentation suggests that about a third of the early return among mothers with rights as compared to those who worked but were without rights stems from residual unobserved stronger labour market attachment. Now some $20 \%$ more mothers with rights are predicted as returning before 8 months than in the benchmark prediction. The results also suggest that that this early return comes mainly from women who would otherwise not return before 35 months rather than bringing forward return from 8 to 34 months (far right hand part of $9 \mathrm{a}$ ). So this model which combines selection and instrumentation suggests that about half of the raw differences in early return by mothers with maternity rights actually stems from differential labour market attachment rather than 
the legal entitlements. However, there remains a substantial impact of these rights on behaviour. These rules drive the formation of two spikes in the pattern of return times. The first, at 3 to 4 months, stems from the termination of paid leave and draws more lower skilled women and those with non-working partners than the second spike at 6 to 7 months. This second spike contains mainly professional and managerial women with working partners. Mothers returning early as a result of having rights would often have not returned by 34 months in the absence of legal entitlements, especially the less skilled. So having rights makes a big difference to return timing.

\section{Conclusions}

The $60 \%$ of mothers with maternity rights return to work rapidly after giving birth, giving large spikes in the return time pattern at the ending of paid leave and unpaid leave at 4 and 7 months respectively. Less skilled mothers and those with no or a non-working partner return disproportionately at the ending of the earlier paid leave spike, while professional/managerial mothers with working partners tend to return at the later spike at the ending of unpaid leave. By contrast, a clear majority of the $40 \%$ of mothers without maternity rights do not return before their child is aged 3 . So on the face of it maternity rights results in profound changes in behaviour.

However, those with rights will differ markedly from those without them. In particular labour market attachment will differ, as having rights requires an extended period of employment prior to the birth. We adopt a three stage strategy for controlling for observed and unobserved differences across the two populations. In the first stage we control for a raft of the obvious observable differences that split these populations, covering age of mother, their education and social class and mothers 
mental and physical health and also characteristics of any partner. We also condition on mothers' attitudes about the age at which they believe that it is safe to leave the child in the care of another adult. This is intended to capture otherwise unobserved differences in tastes or preferences across mothers. This conditioning makes very little difference to the raw results. The large spikes in the return time distributions are clearly not driven by observable differences in characteristics.

The second stage is to restrict our comparative sample to those who worked during the pregnancy. These women thus also have recent labour market attachment and such as might be expected to return to work earlier than other women without maternity rights. It is estimated that 31 percent more mothers with rights return to work at the two spike points than would occur for similar people without rights but who worked in pregnancy. The first two stages of conditioning thus make relatively little difference to the estimated size of the spikes at 3 and 7 months as in the raw data $36 \%$ more mothers with rights return at these spikes than those without them.

The third stage is to use instrumental variables to identify women who lost their maternity rights for reasons unconnected to their labour market attachment. Here we exploit the fact that women need to work up to 11 weeks before the expected due date to maintain their rights. This even applies to stopping early for medical reasons. We explore evidence of mothers experiencing health problems during the pregnancy, whose workplace is smoky, noise or difficult to commute to and those who move because their partner has changed jobs. These events strongly predict women stopping before 11 weeks in advance of the due date and hence predict why some mothers lost maternity rights. Using this information as our instrument set allows us to control for any residual unobserved differences between mothers with rights and the rest of the sample. This final stage of conditioning reduces the proportion of mothers predicted to return at the two spikes to just 19 percentage points more than 
would occur without maternity rights. This suggests that women with rights differ from other mothers in important but otherwise unobserved dimensions. The model also suggests that most of these mothers who are induced to return before 8 months would, in the absence of rights, stay out until the child is at least 3 years old.

Having maternity rights affects the return behaviour of managerial and professional women more than those in less skilled occupations. But the lower skill groups do return disproportionately at the earlier spike coincident with the ending of unpaid leave. Mothers in lower skilled occupations do make use of paid leave but then either return to work at 4 months or stay out till the child is much older. In a similar vein, women with working partners with maternity rights tend to stay out to the end of unpaid leave whereas those with no or a non-working partner tend more to return at the end of paid leave. The government is currently proposing to extend paid leave to 6 months and unpaid leave to a year. Based on the evidence seen here we would expect to see large spikes form at these return times consistent with these new dates. Our model would predict that around 8 percent of mothers with rights would move from the current spike at 3 months to the new one at 6 months. This will mainly consist of less skilled mothers and those without a working partner. In addition, a small number of these groups who currently cannot afford to continue on unpaid leave and do not return until the child is aged at least 3 will switch all the way to the 6 month ending of paid leave. Our model also suggests that almost all mothers who currently return at the ending of unpaid leave 7 months will continue to 12 months under the new rules. 


\section{$\underline{\text { References }}$}

Desai, S, and Waite, L (1991) "Women's employment during pregnancy and after the first birth: Occupational characteristics and work commitment" American Sociological Review 56(4), 551-566

Farber, H. (1993) The Incidence and Cost of Job Loss:1982-9, Brookings Papers on Economic Activity: Microeconomics, 73-122

Glass, J, and Riley, L (1998) "Family responsive policies and employee retention following childbirth" Social Forces 76(4), 1401-1435

Gregg, P, and Wadsworth, J, (2000) Mind the Gap, Please: The Changing Nature of Entry Jobs in Britain, Economica, Vol. 67 No.268, 499-524

Hujer, R, Maurer, K, and Wellner, M (1997) "Estimating the effect of training on unemployment duration in West Germany: A discrete hazard-rate model with instrumental variables" mimeo Johann Wolfgang Goethe-University

Jacobsen, L. LaLonde, R. and Sullivan, D. (1993) Earnings of Displaced Workers, American Economic Review, vol. 83, 685-709

Narendranathan, W and Stewart, MB (1993) "How does the benefit effect vary as unemployment spells lengthen?" Journal of Applied Econometrics 8(4), 361381

Ondrich, J, Speiss, CK, Yang, Q and Wagner, GG (1998) "The liberalization of maternity leave policy and the return to work after childbirth in Germany" IZA Discussion Paper No. 21

Ross, K (1998) "Labor pains: The effect of the Family and Medical Leave Act on the return to paid work after childbirth" Focus 20(1), 34-36, University of WisconsinMadison Institute for Research on Poverty 
Smith, K, Downs, B, and O'Connell, M (2001) “Maternity leave and employment patterns: 1961-1995", Current Population Reports, P70-P79. US Census Bureau, Washington DC

Waldfogel, J (1998) "The family gap for young women in the United States and Britain: Can maternity leave make a difference?" Journal of Labor Economics 16(3), 505-545

Waldfogel, J (1999) "The Impact of the Family and Medical Leave Act" Journal of Policy Analysis and Management 18(2), 281-302

Waldfogel, J, and Berger, LM (2001) "Maternity leave and the employment of new mothers in the United States", mimeo Columbia University 
FIG 2(a)

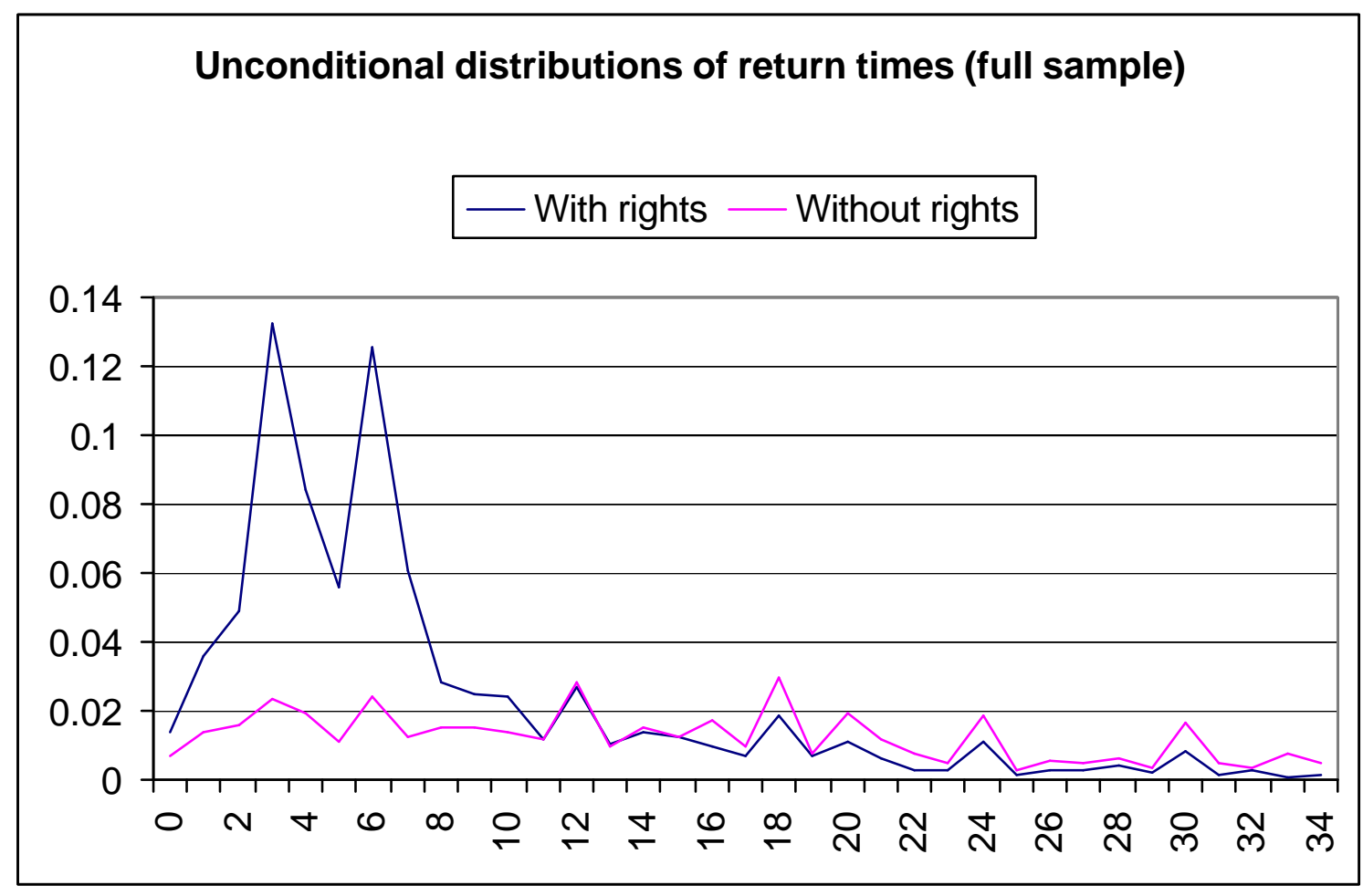

FIG 2(b)

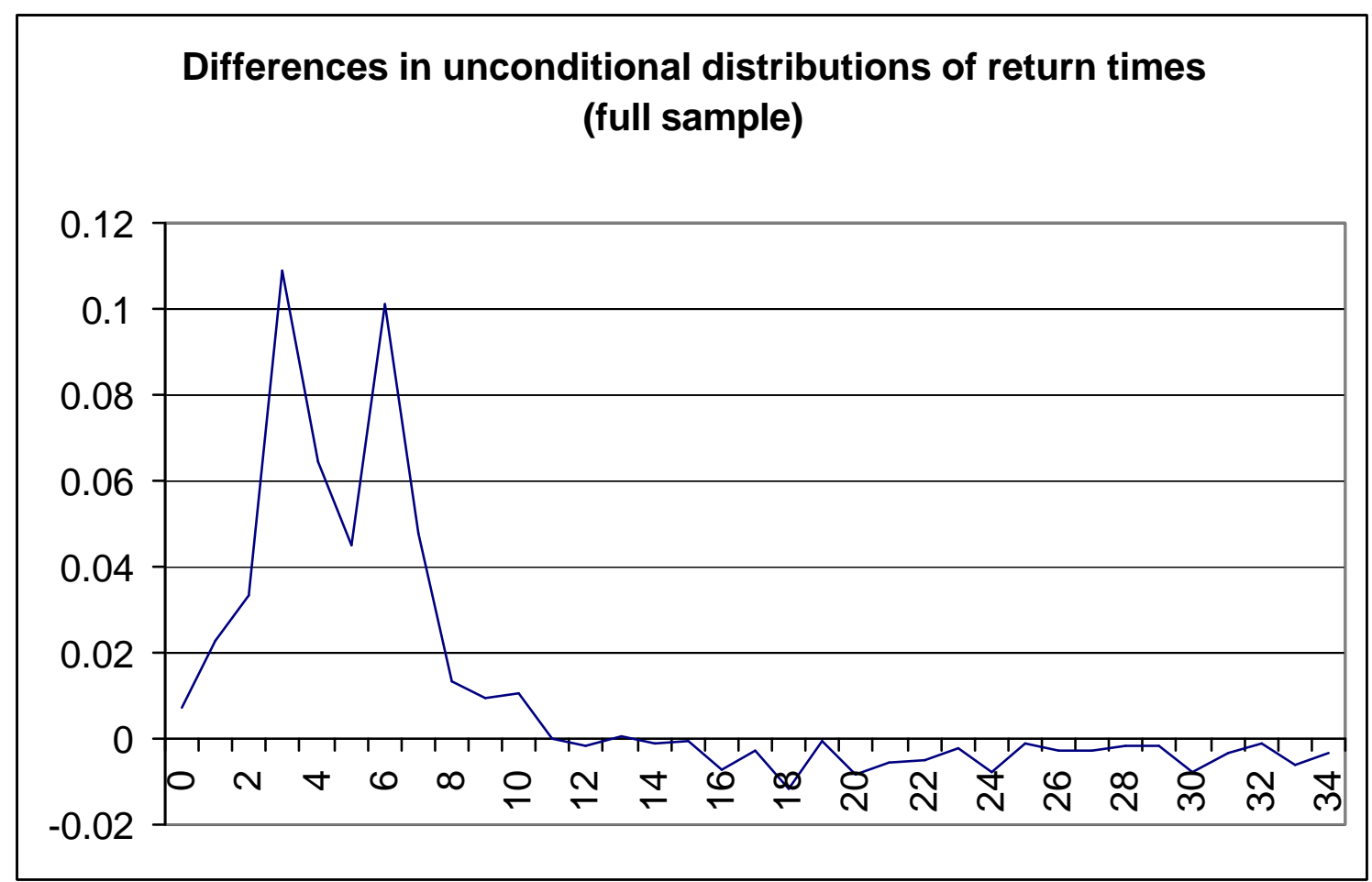


FIG 3(a)

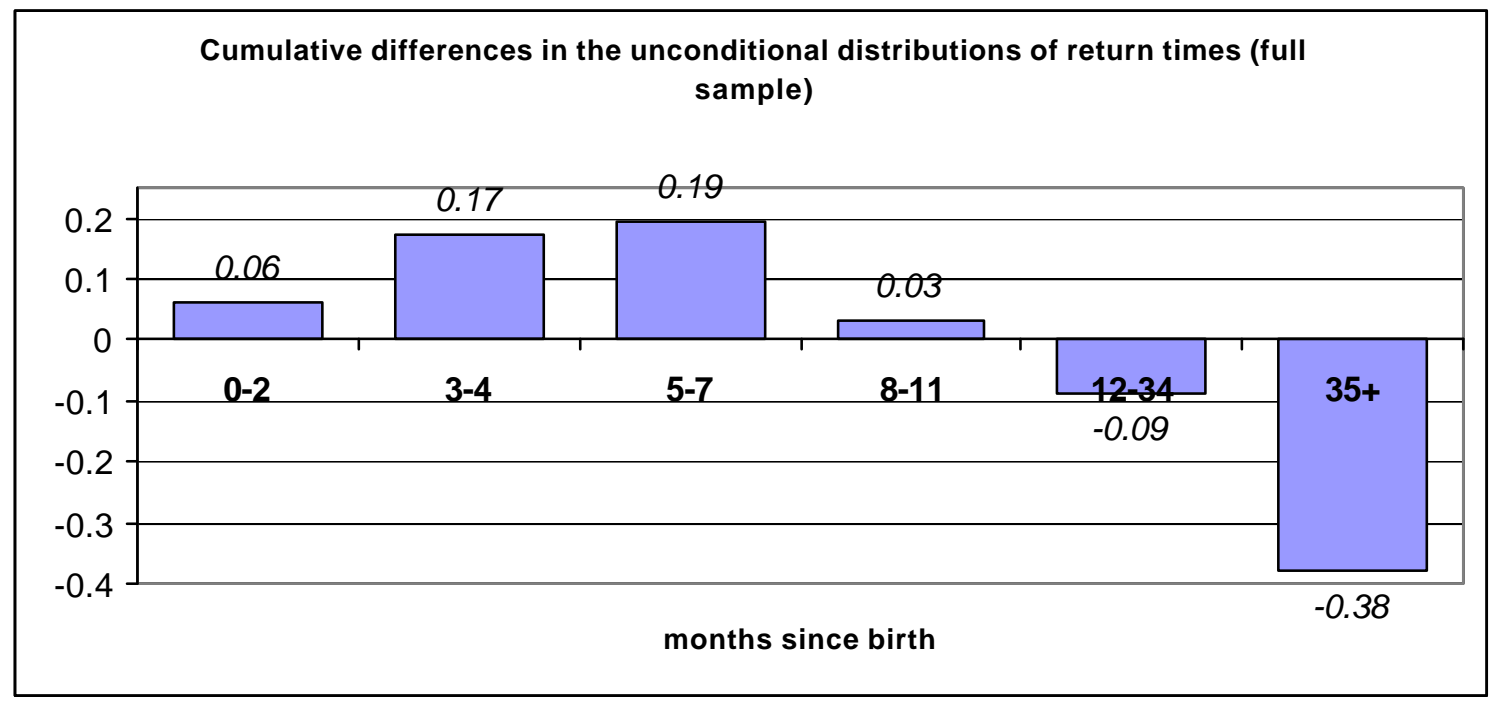

FIG 3(b)

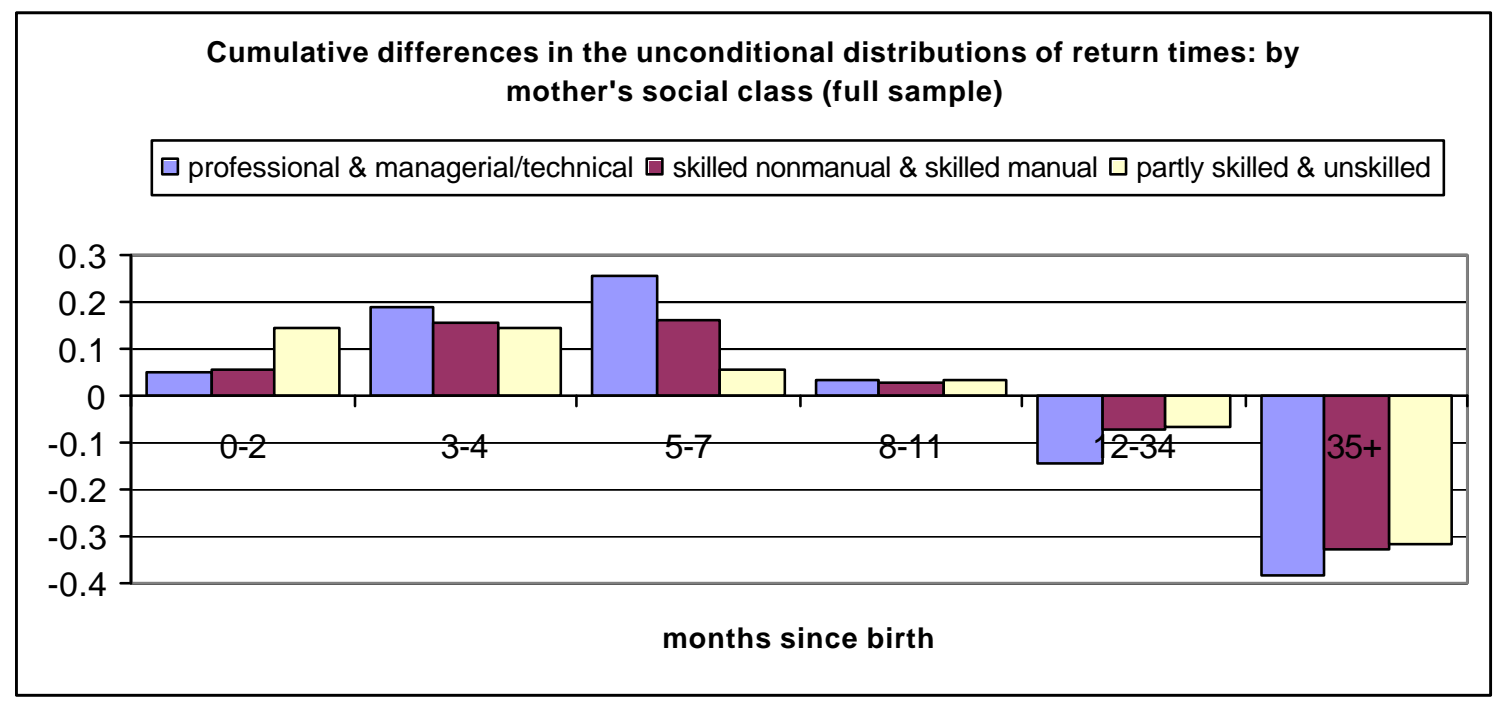

FIG 3(c)

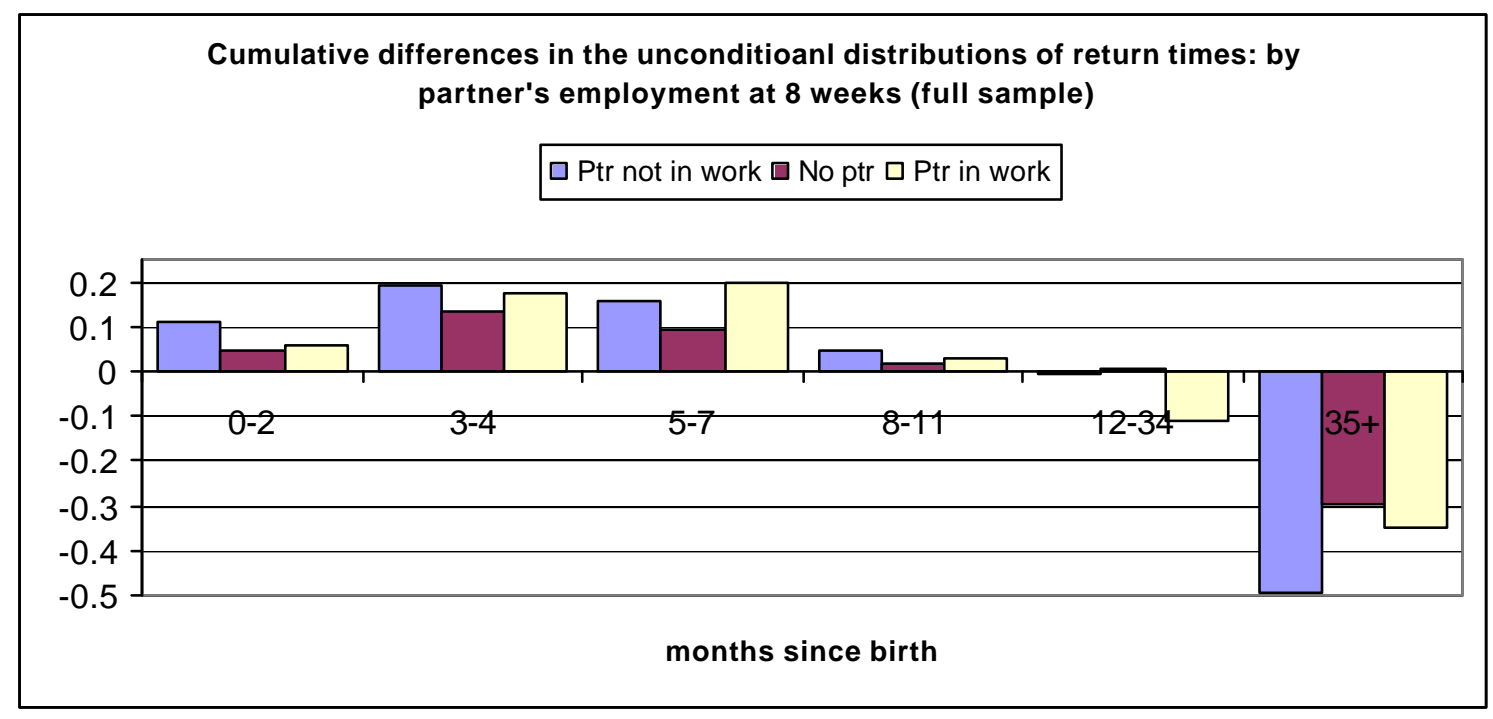


FIG 4(a)

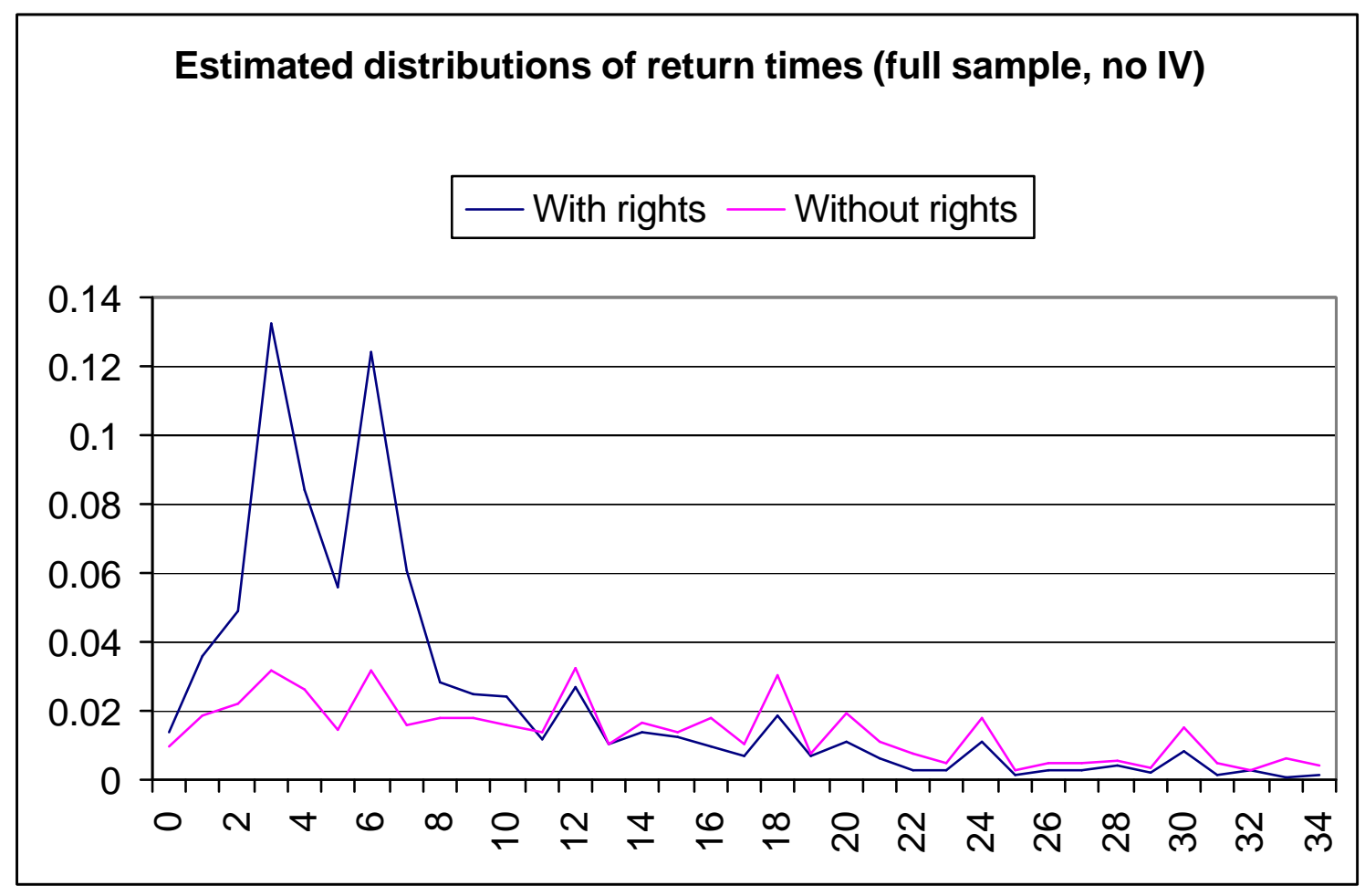

FIG 4(b)

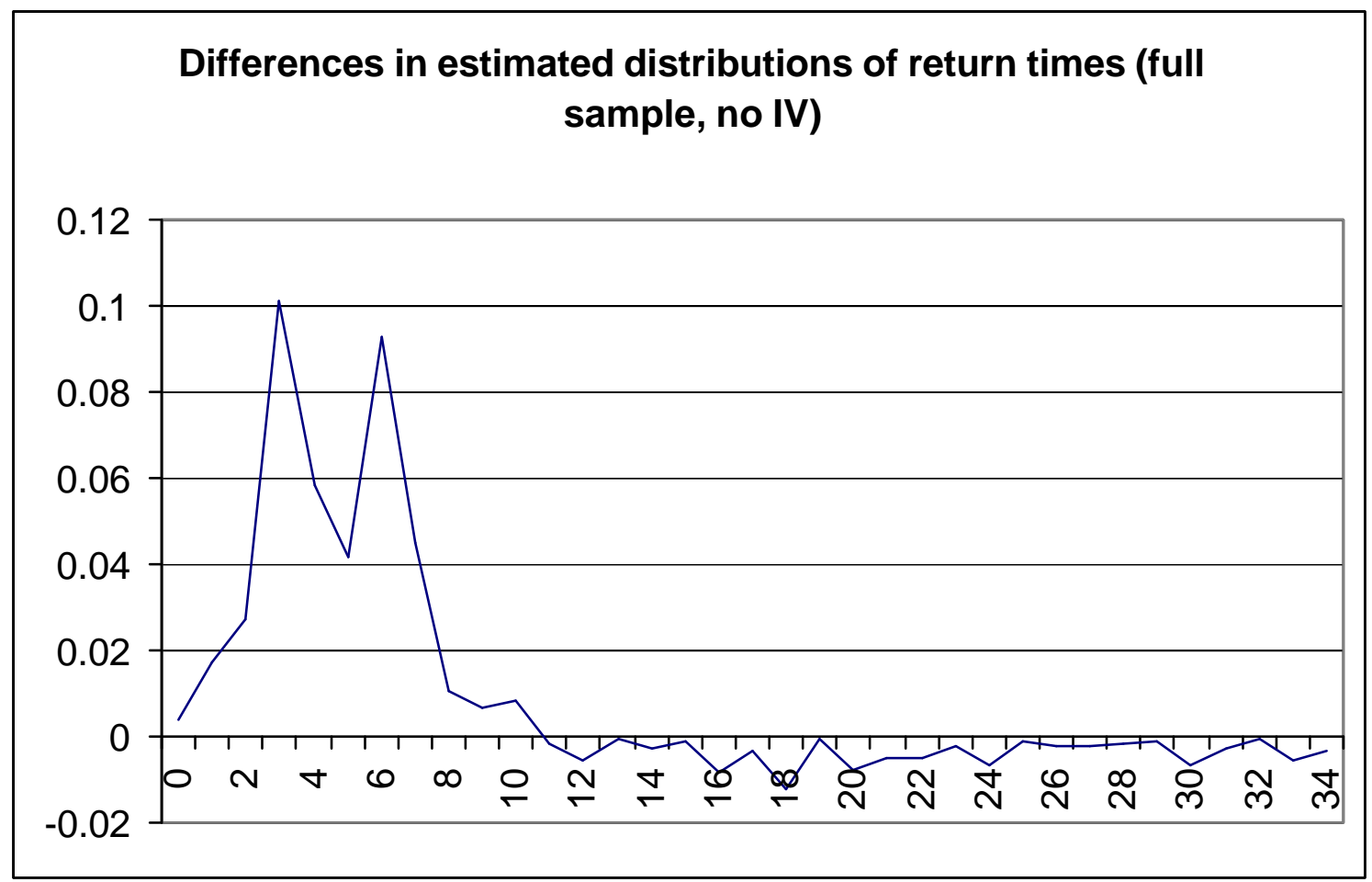


FIG 5(a)

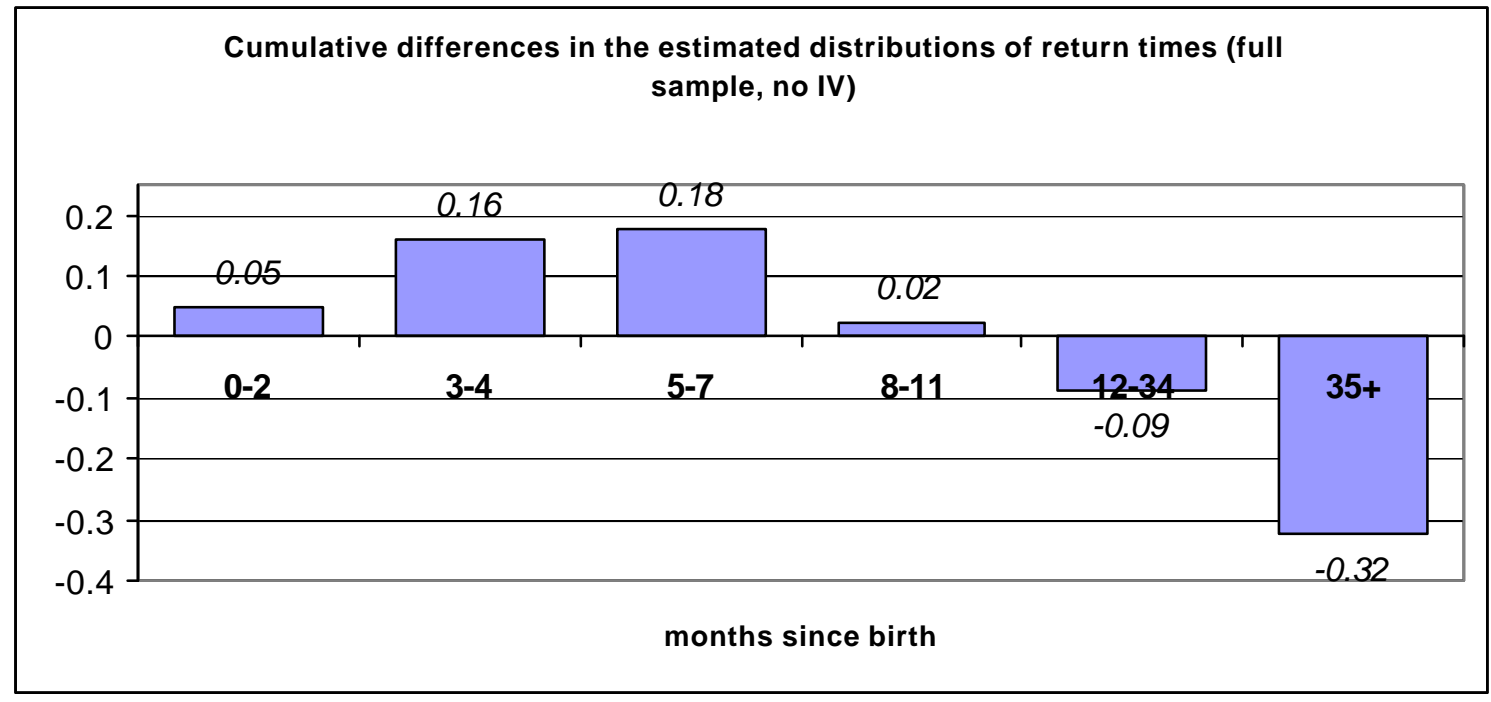

FIG 5(b)

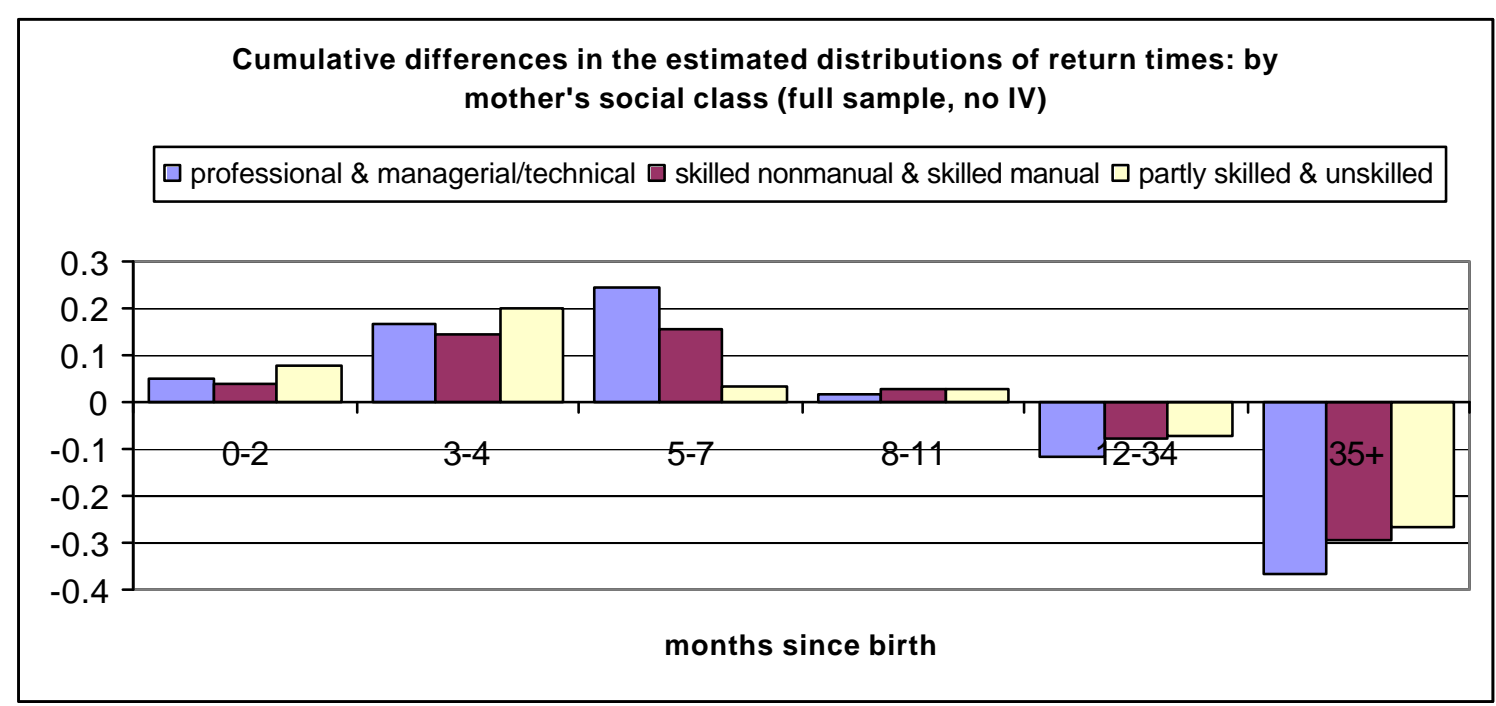

FIG 5(c)

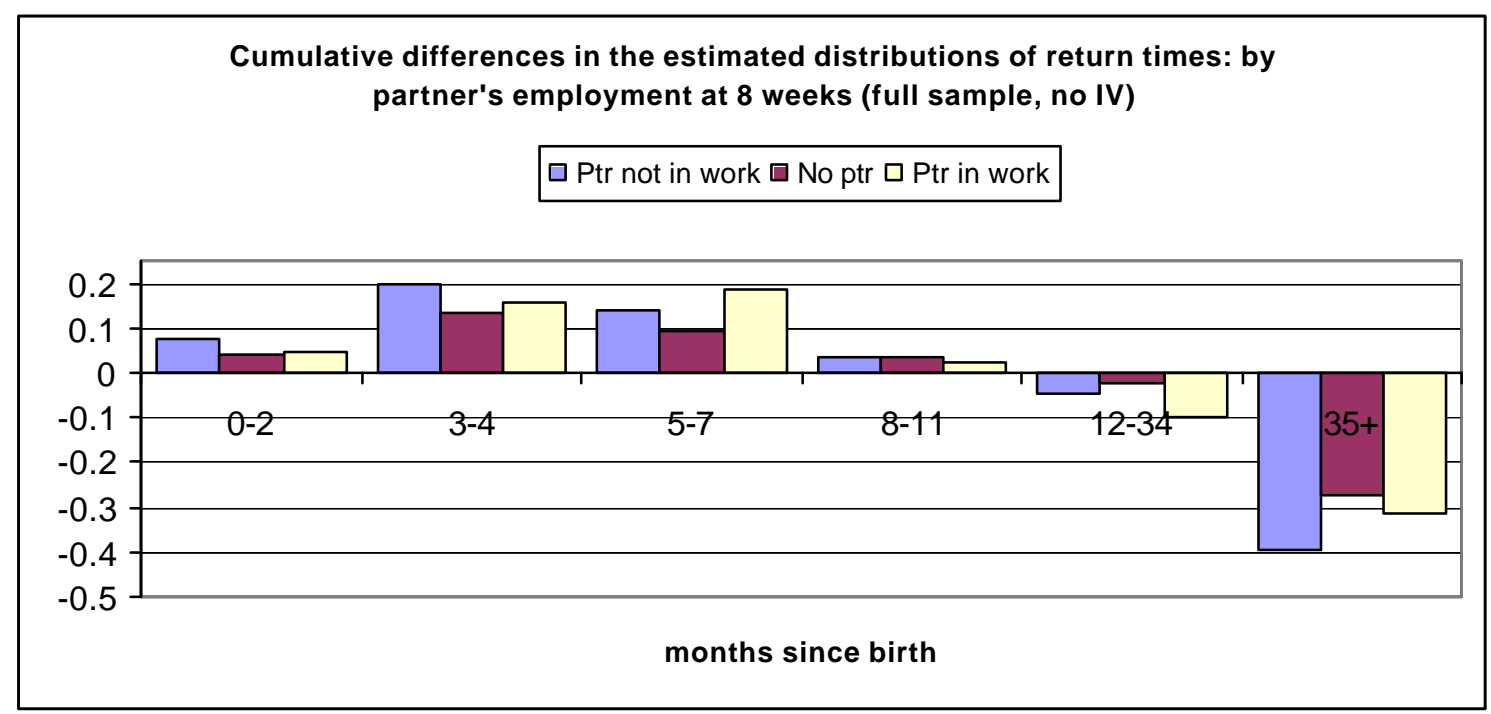


FIG 6(a)

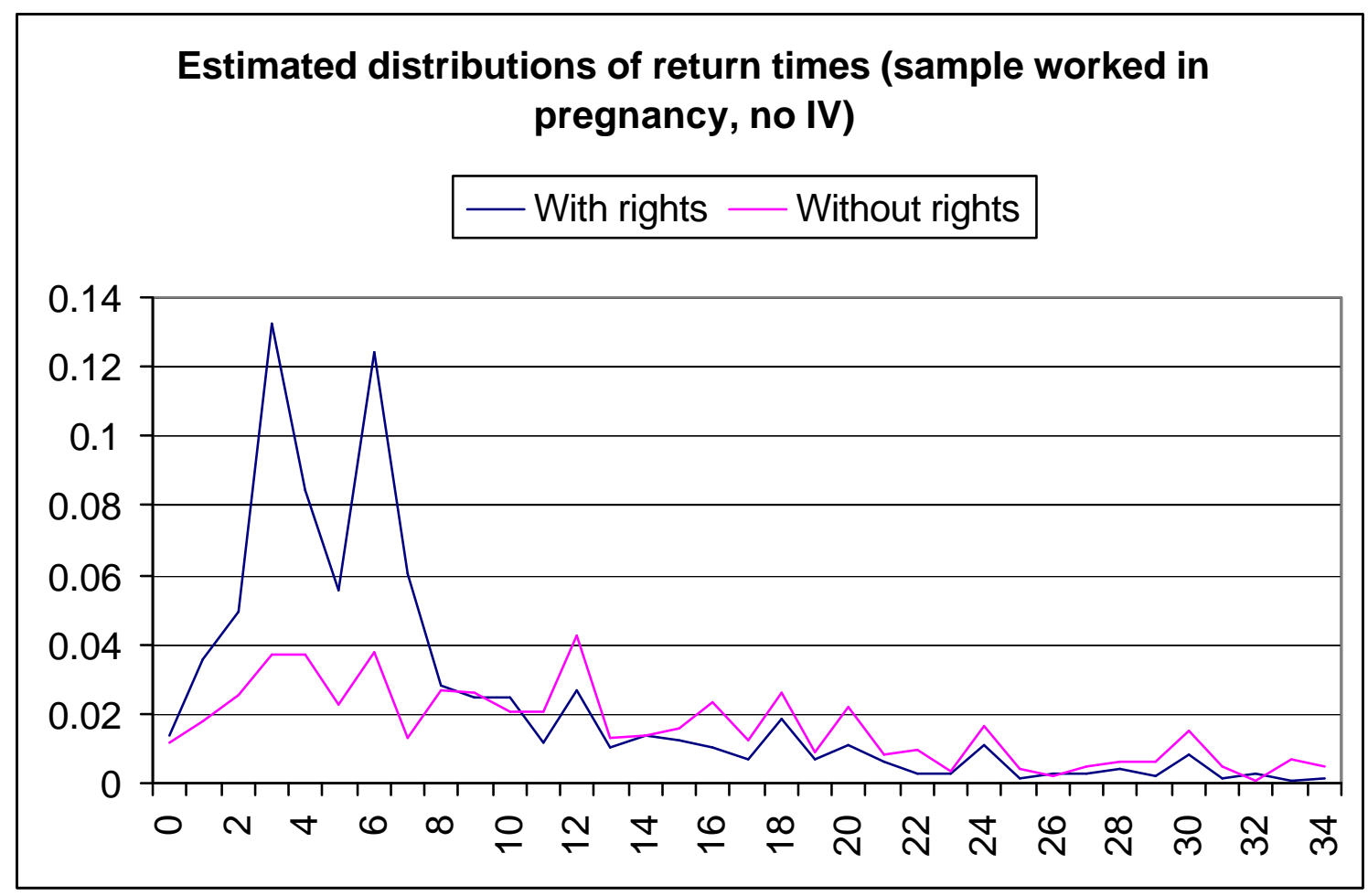

FIG 6(b)

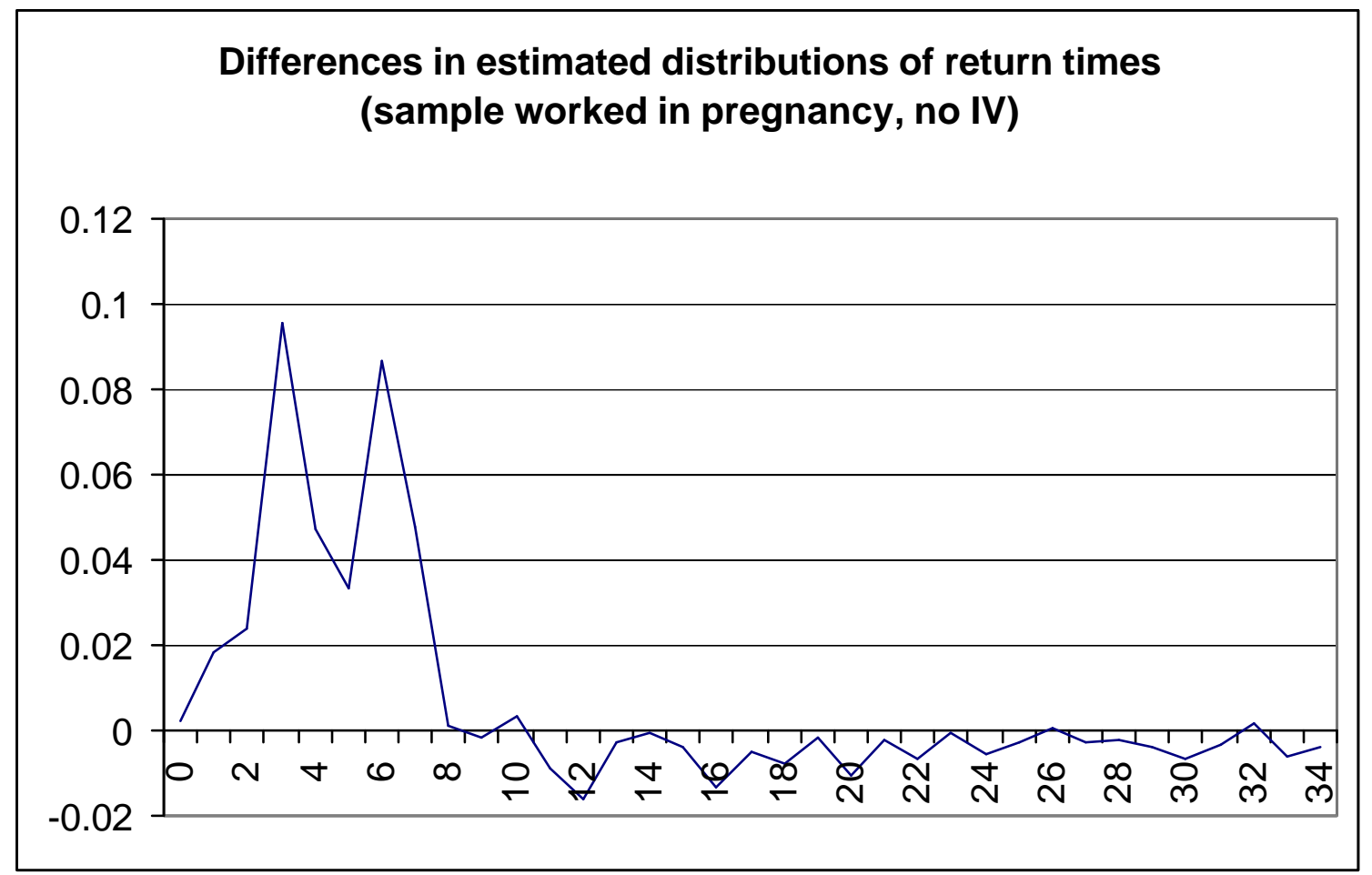


FIG 7(a)

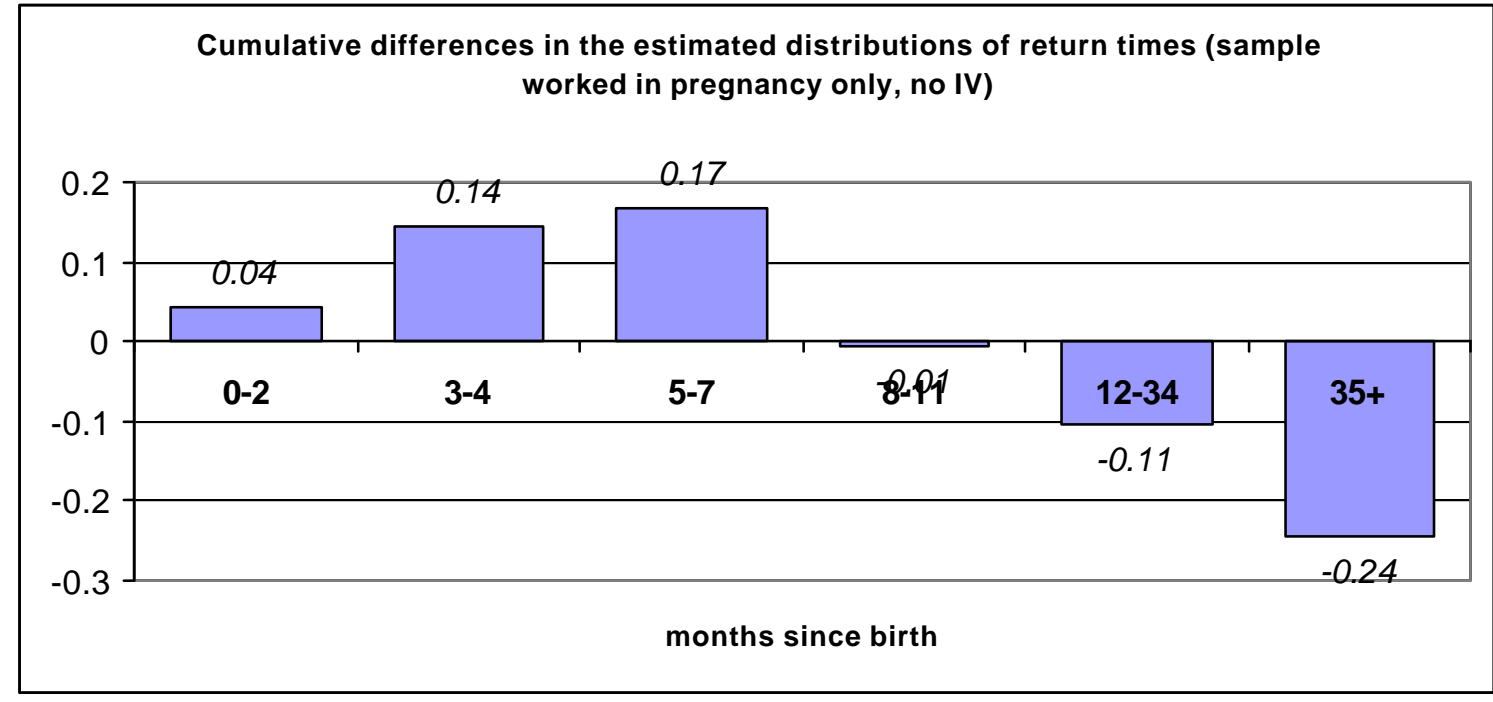

FIG 7(b)

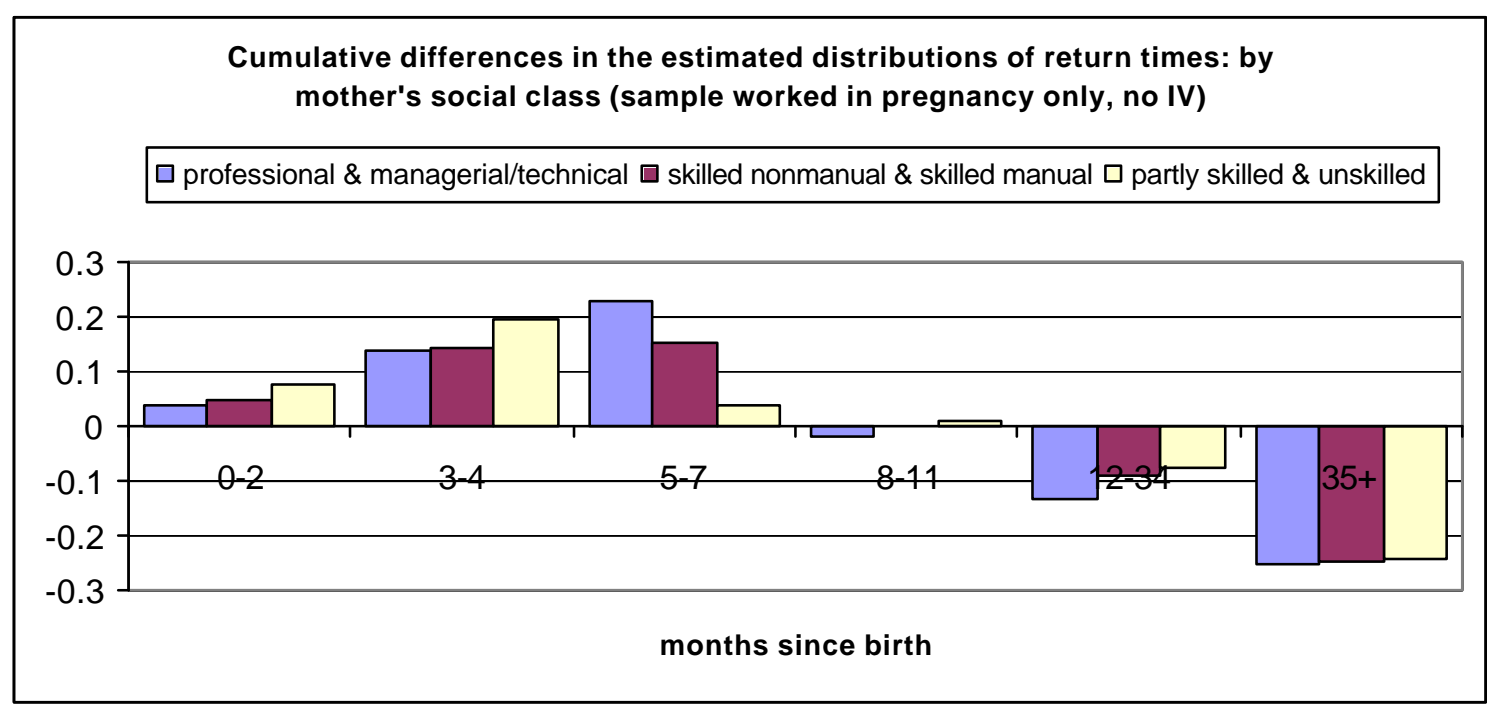

FIG 7(c)

Cumulative differences in the estimated distributions of return times: by partner's employment at 8 weeks (sample worked in pregnancy only, no IV)

$\square$ Ptr not in work $\square$ No ptr $\square$ Ptr in work

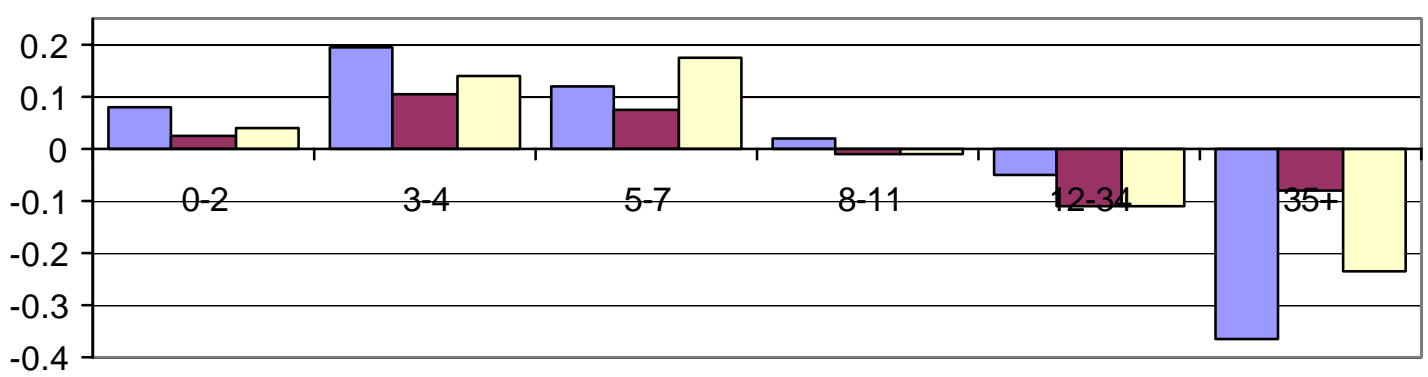

months since birth 
FIG 8(a)

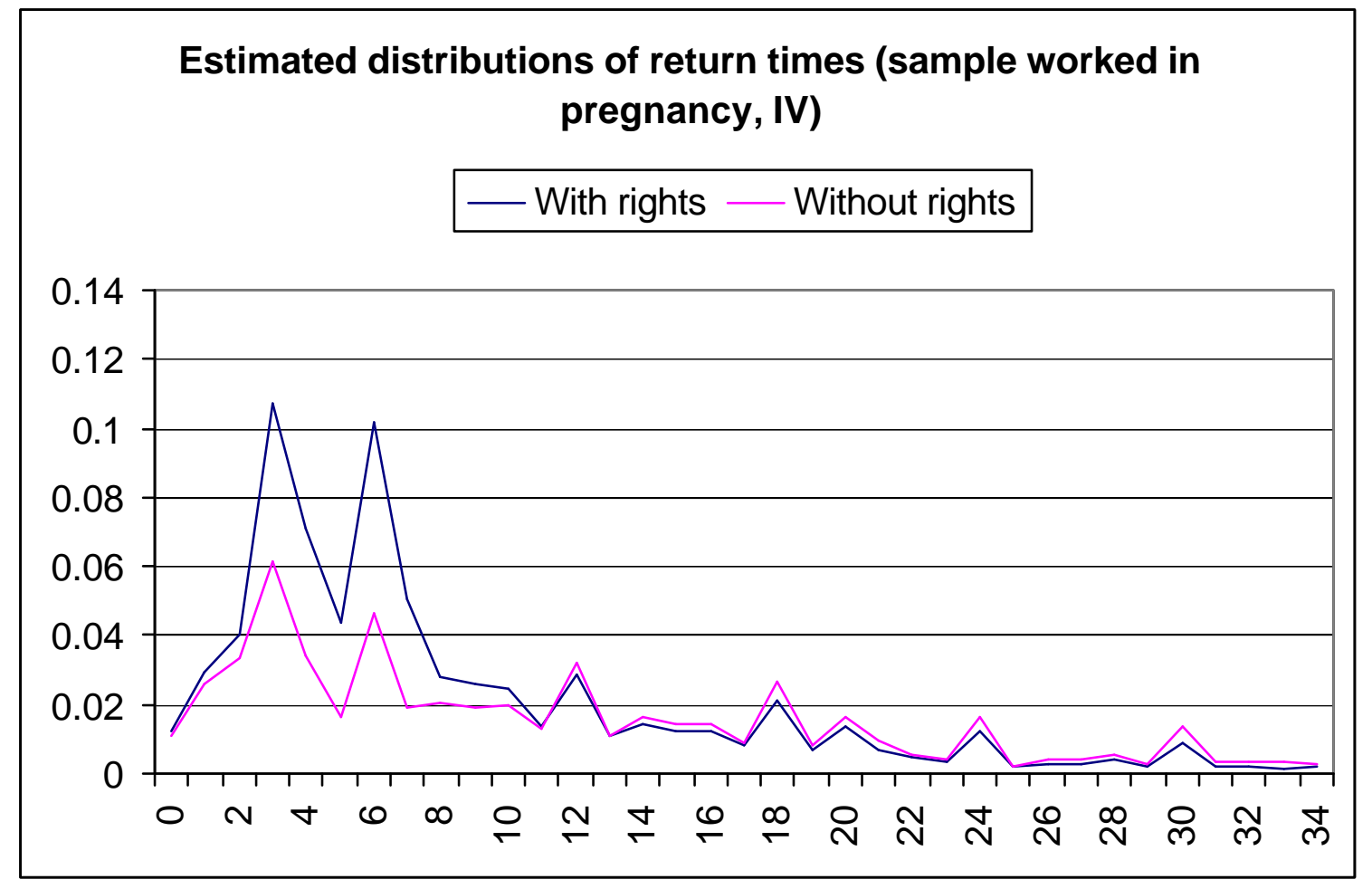

FIG 8(b)

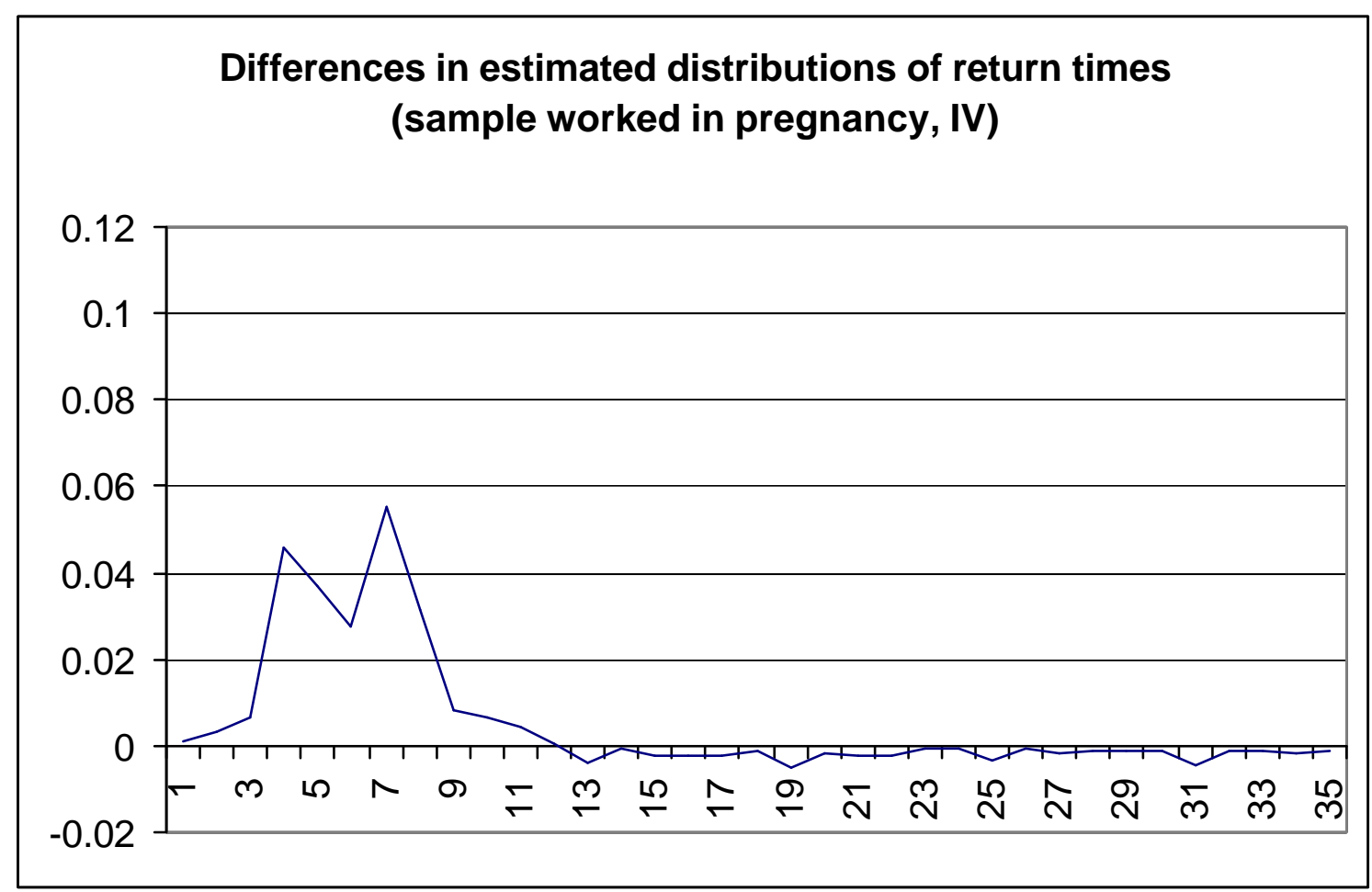


FIG 9(a)

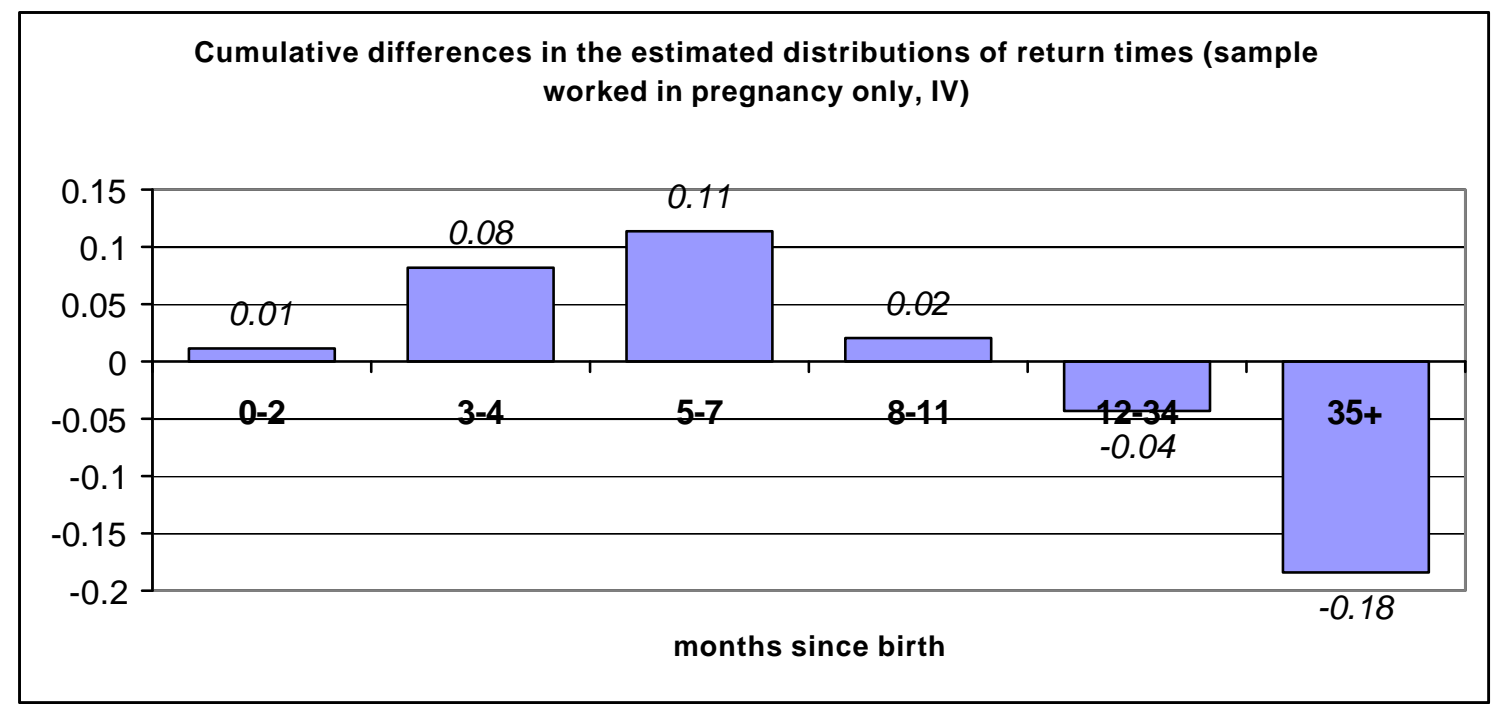

FIG 9(b)

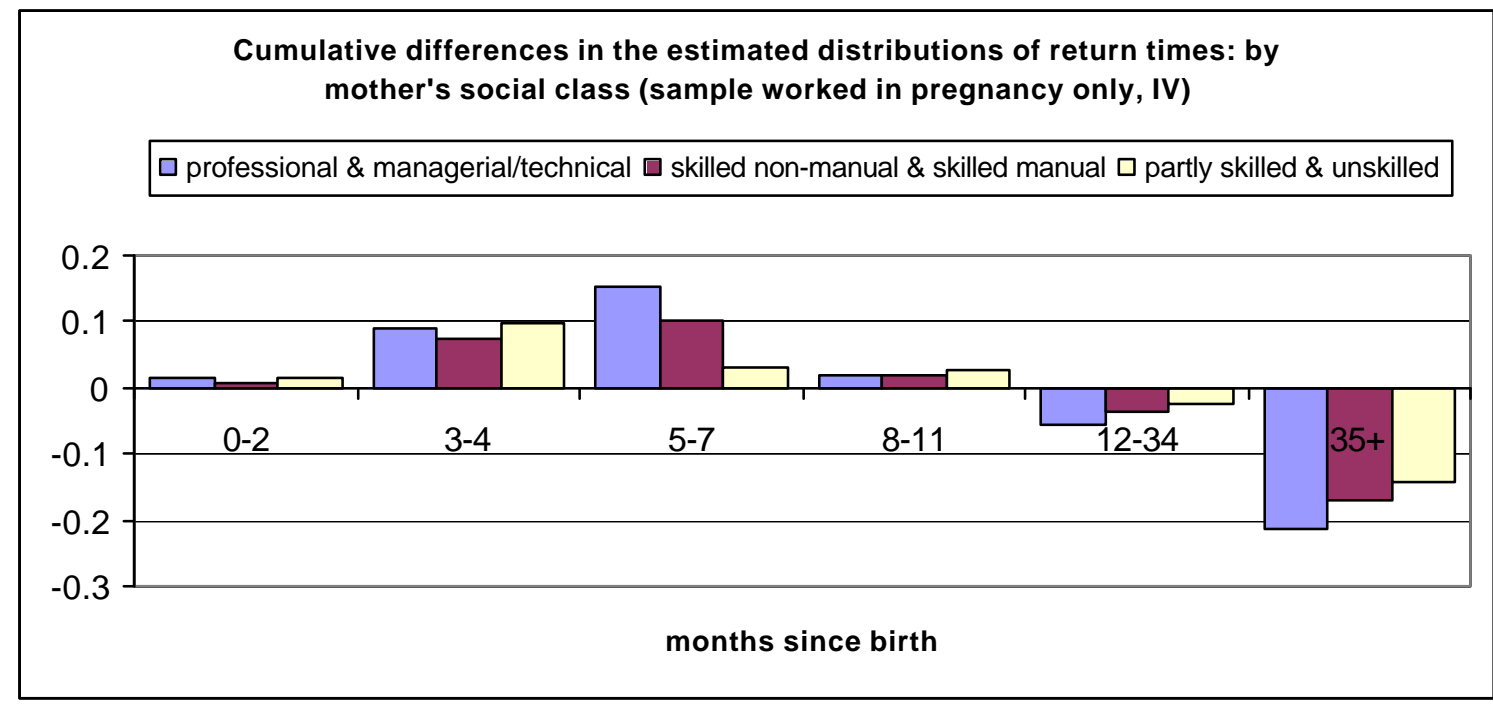

FIG 9(c)

Cumulative differences in the estimated distributions of return times: by partner's employment at 8 weeks (sample worked in pregnancy only, IV)

$\square$ Ptr not in work $\square$ No ptr $\square$ Ptr in work

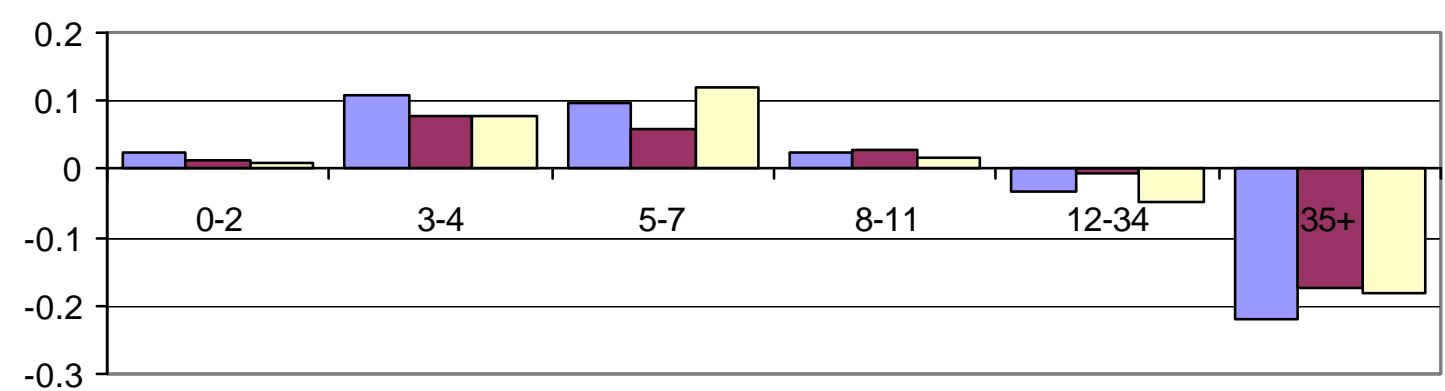

months since birth 
Table 1: Attitudes to child care by rights status and return time

\begin{tabular}{|c|c|c|c|c|}
\hline & Minimum as & e child can & oe left in anoth & ger's care ${ }^{*}$ \\
\hline & $0-5$ mths & $6-11 \mathrm{mths}$ & $12-35 \mathrm{mths}$ & 36 mths + \\
\hline$\%$ who answered question & 27.5 & 29.9 & 13.2 & 29.4 \\
\hline Of which: & & & & \\
\hline With rights & 0.84 & 0.75 & 0.51 & 0.40 \\
\hline Without rights & 0.16 & 0.25 & 0.49 & 0.60 \\
\hline With rights & & & & \\
\hline Return date & & & & \\
\hline 0 to 4 months & 0.51 & 0.20 & 0.22 & 0.24 \\
\hline 5 to 7 months & 0.25 & 0.38 & 0.15 & 0.09 \\
\hline after 7 months ${ }^{\star *}$ & 0.24 & 0.42 & 0.63 & 0.67 \\
\hline Without rights & & & & \\
\hline Return date & & & & \\
\hline 0 to 4 months & 0.12 & 0.10 & 0.07 & 0.06 \\
\hline 5 to 7 months & 0.07 & 0.06 & 0.04 & 0.04 \\
\hline after 7 months ${ }^{* *}$ & 0.81 & 0.83 & 0.90 & 0.90 \\
\hline $\begin{array}{l}{ }^{*} \text { Response to the question } \\
\text { alright for a mother to leav } \\
\text { during the day?' } \\
{ }^{* *} \text { or not at all }\end{array}$ & $\begin{array}{l}\text { hat is the } y \\
\text { er child regu }\end{array}$ & $\begin{array}{l}\text { ungest age } \\
\text { arly in the }\end{array}$ & $\begin{array}{l}\text { at which you t } \\
\text { re of another }\end{array}$ & $\begin{array}{l}\text { hink it is } \\
\text { person }\end{array}$ \\
\hline $\begin{array}{l}\text { Shaded figures highlight th } \\
\text { status, for whom the windo } \\
\text { was earlier than they repor } \\
\text { care. }\end{array}$ & $\begin{array}{l}\text { proportion of } \\
\text { in which the } \\
\text { d }\end{array}$ & $\begin{array}{l}\text { mothers, wit } \\
\text { r return time } \\
\text { ght" to leave }\end{array}$ & $\begin{array}{l}\text { th given belief } \\
\text { fell (e.g. } 0 \text { to } \\
\text { the child in a }\end{array}$ & $\begin{array}{l}s \text { and rights } \\
4 \text { months) } \\
\text { nother's }\end{array}$ \\
\hline
\end{tabular}


Table 2: Cross-tabulations of labour market attachment and return dates: full sample and by selected characteristics

\begin{tabular}{|c|c|c|c|c|c|}
\hline \multirow[b]{2}{*}{$\begin{array}{c}\text { Labour market } \\
\text { atachment }\end{array}$} & \multirow[b]{2}{*}{$\begin{array}{c}\% \text { of } \\
\text { population }\end{array}$} & \multicolumn{4}{|c|}{ Proportion returning: } \\
\hline & & $0-4$ mths & 5-7mth & 8-34 mths & $\begin{array}{c}\text { not by } 34 \\
\text { months }\end{array}$ \\
\hline Total & 100.0 & 22.8 & 17.0 & 27.5 & 32.8 \\
\hline With rights & 62.8 & 31.6 & 24.2 & 25.5 & 18.7 \\
\hline Some attachment & 9.4 & 12.0 & 7.3 & 37.1 & 43.6 \\
\hline Weak attachment & 27.9 & 6.6 & 3.9 & 28.7 & 60.9 \\
\hline \multicolumn{6}{|c|}{ BY SOCIAL CLASS } \\
\hline \multicolumn{6}{|c|}{ Professional and managerial/technical (34.1\% of sample) } \\
\hline \multirow[b]{2}{*}{$\begin{array}{l}\text { Labour market } \\
\text { atachment }\end{array}$} & \multirow[b]{2}{*}{$\begin{array}{c}\% \text { of } \\
\text { population }\end{array}$} & \multicolumn{4}{|c|}{ Proportion returning: } \\
\hline & & $0-4$ mths & 5-7mth & 8-34 mths & $\begin{array}{c}\text { not by } 34 \\
\text { months }\end{array}$ \\
\hline Total & 100.0 & 27.7 & 25.9 & 24.6 & 21.8 \\
\hline With rights & 76.1 & 33.4 & 32.0 & 21.9 & 12.6 \\
\hline Some attachment & 7.4 & 16.3 & 8.8 & 37.1 & 37.9 \\
\hline Weak attachment & 16.5 & 6.7 & 5.2 & 31.5 & 56.6 \\
\hline \multicolumn{6}{|c|}{ Skilled nonmanual \& skilled manual ( $42.1 \%$ of sample) } \\
\hline \multirow[b]{2}{*}{$\begin{array}{l}\text { Labour market } \\
\text { atachment }\end{array}$} & \multirow[b]{2}{*}{$\begin{array}{c}\% \text { of } \\
\text { population }\end{array}$} & \multicolumn{4}{|c|}{ Proportion returning: } \\
\hline & & $0-4$ mths & 5-7mth & 8-34 mths & $\begin{array}{c}\text { not by } 34 \\
\text { months }\end{array}$ \\
\hline Total & 100.0 & 22.5 & 15.0 & 29.1 & 33.5 \\
\hline With rights & 66.8 & 29.4 & 20.4 & 27.7 & 22.6 \\
\hline Some attachment & 9.1 & 10.6 & 5.7 & 39.0 & 44.7 \\
\hline Weak attachment & 24.1 & 7.8 & 3.5 & 29.2 & 59.5 \\
\hline \multicolumn{6}{|c|}{ Partly skilled \& unskilled ( $9.0 \%$ of sample) } \\
\hline \multirow[b]{2}{*}{$\begin{array}{c}\text { Labour market } \\
\text { atachment }\end{array}$} & \multirow[b]{2}{*}{$\begin{array}{c}\% \text { of } \\
\text { population }\end{array}$} & \multicolumn{4}{|c|}{ Proportion returning: } \\
\hline & & $0-4$ mths & 5-7mth & 8-34 mths & $\begin{array}{c}\text { not by } 34 \\
\text { months }\end{array}$ \\
\hline Total & 100.0 & 25.3 & 10.9 & 29.0 & 24.8 \\
\hline With rights & 61.0 & 36.6 & 13.1 & 27.8 & 22.5 \\
\hline Some attachment & 13.1 & 9.7 & 8.0 & 35.4 & 46.9 \\
\hline Weak attachment & 25.9 & 6.7 & 7.1 & 28.6 & 57.6 \\
\hline \multicolumn{6}{|c|}{ BY PARTNER'S EMPLOYMENT STATUS A'T 8 WEEKS } \\
\hline \multicolumn{6}{|c|}{ Partner not in work ( $10.0 \%$ of sample) } \\
\hline \multirow[b]{2}{*}{$\begin{array}{c}\text { Labour market } \\
\text { atachment }\end{array}$} & \multirow[b]{2}{*}{$\begin{array}{c}\% \text { of } \\
\text { population }\end{array}$} & \multicolumn{4}{|c|}{ Proportion returning: } \\
\hline & & $0-4 \mathrm{mths}$ & 5-7mth & 8-34 mths & $\begin{array}{c}\text { not by } 34 \\
\text { months }\end{array}$ \\
\hline Total & 100.0 & 19.6 & 10.4 & 24.7 & 45.3 \\
\hline With rights & 45.3 & 36.0 & 18.9 & 26.8 & 18.2 \\
\hline Some attachment & 12.6 & 7.5 & 5.8 & 29.2 & 57.5 \\
\hline Weak attachment & 42.1 & 5.5 & 2.5 & 21.1 & 70.9 \\
\hline & No part & $\operatorname{ter}(2.7 \%$ & sample) & & \\
\hline & & & Proporti & returning: & \\
\hline $\begin{array}{c}\text { Labour market } \\
\text { atachment }\end{array}$ & \begin{tabular}{|c|}
$\begin{array}{c}\% \\
\%\end{array}$ of \\
population
\end{tabular} & $0-4 \mathrm{mths}$ & 5-7mth & 8-34 mths & $\begin{array}{c}\text { not by } 34 \\
\text { months }\end{array}$ \\
\hline Total & 100.0 & 15.2 & 5.9 & 25.8 & 53.1 \\
\hline With rights & 4 & 25.0 & 10.7 & 27.1 & 37.7 \\
\hline Some attachment & 15.2 & 10.3 & 2.6 & 33.3 & 53.9 \\
\hline Weak attachment & 37.1 & 5.3 & 1.1 & 21.1 & 72.6 \\
\hline & Partner in & ork $(81.5$ & of samp & & \\
\hline & & & Proport & returning: & \\
\hline $\begin{array}{c}\text { Labour market } \\
\text { atachment }\end{array}$ & $\begin{array}{c}\% \text { of } \\
\text { population }\end{array}$ & $0-4$ mths & 5-7mth & 8-34 mths & $\begin{array}{c}\text { not by } 34 \\
\text { months }\end{array}$ \\
\hline Total & 100.0 & 23.5 & 18.5 & 28.2 & 29.8 \\
\hline With rights & 65.8 & 31.4 & 25.3 & 25.6 & 17.8 \\
\hline Some attachment & 8.7 & 12.8 & 8.1 & 39.8 & 39.3 \\
\hline Weak attachment & 25.5 & 6.9 & 4.5 & 31.2 & 57.5 \\
\hline
\end{tabular}


Table 3: Instruments used in the first stage probit model

\begin{tabular}{|c|c|c|c|c|}
\hline & \multirow{2}{*}{$\begin{array}{l}\text { 1ST STAGE } \\
\text { ESTIMATES }\end{array}$} & \multicolumn{3}{|c|}{ MEANS AND S.D'S OF VARIABLES } \\
\hline & & \multirow[b]{2}{*}{$\begin{array}{l}\text { All worked in } \\
\text { preanancy }\end{array}$} & \multirow[b]{2}{*}{ With rights } & \multirow{2}{*}{$\begin{array}{c}\text { Without rights } \\
\text { but worked in } \\
\text { preanancy }\end{array}$} \\
\hline & & & & \\
\hline & coef & mean S.D. R & mean S.D. R & \begin{tabular}{|ll} 
mean S.D. $\mathrm{R}$ \\
\end{tabular} \\
\hline \multicolumn{5}{|l|}{ Events in pregnancy } \\
\hline TIMEAVON & & 0.98 & 0.99 & 0.98 \\
\hline \begin{tabular}{|l} 
no \\
yes
\end{tabular} & \begin{tabular}{|c|c|}
\multicolumn{2}{c|}{ BASE } \\
$-0.464^{\star \star *}$ & 0.099 \\
\end{tabular} & $\begin{array}{ll}0.95 & 0.21 \\
0.05 & 0.21 \\
\end{array}$ & $\begin{array}{ll}0.97 & 0.18 \\
0.03 & 0.18 \\
\end{array}$ & $\begin{array}{ll}0.91 & 0.29 \\
0.09 & 0.29 \\
\end{array}$ \\
\hline MOVED & & 0.96 & 0.96 & 0.95 \\
\hline $\begin{array}{l}\text { no } \\
\text { yes, no new job for ptr } \\
\text { yes, \& ptr had new job }\end{array}$ & \begin{tabular}{|ll|}
\multicolumn{2}{|c|}{ BASE } \\
$-0.096^{*}$ & 0.058 \\
$-0.175^{*}$ & 0.119 \\
\end{tabular} & $\begin{array}{ll}\mathbf{0 . 7 4} & 0.44 \\
\mathbf{0 . 2 3} & 0.42 \\
\mathbf{0 . 0 3} & 0.17 \\
\end{array}$ & $\begin{array}{ll}\mathbf{0 . 7 7} & 0.42 \\
\mathbf{0 . 2 0} & 0.40 \\
\mathbf{0 . 0 3} & 0.16 \\
\end{array}$ & $\begin{array}{ll}\mathbf{0 . 6 5} & 0.48 \\
\mathbf{0 . 2 9} & 0.46 \\
\mathbf{0 . 0 6} & 0.23 \\
\end{array}$ \\
\hline WLESPRE & & 0.94 & 0.95 & 0.91 \\
\hline $\begin{array}{l}0-4 \\
5-9 \\
10-14 \\
15-19 \\
20+ \\
\\
\text { Joint test of events in } \\
\text { pregnancy variables: } \\
\text { Work-related variables } \\
\end{array}$ & \begin{tabular}{||cc|}
\multicolumn{2}{|c|}{ BASE } \\
$-0.163^{* * *}$ & 0.061 \\
$-0.338^{* * *}$ & 0.071 \\
$-0.369^{* * *}$ & 0.090 \\
$-0.634^{* * *}$ & 0.089 \\
& \\
chi2 $(10)=96.29$ \\
Prob $>$ chi2 $=0.0000$
\end{tabular} & $\begin{array}{ll}\mathbf{0 . 3 8} & 0.48 \\
\mathbf{0 . 3 0} & 0.46 \\
\mathbf{0 . 1 6} & 0.37 \\
\mathbf{0 . 0 8} & 0.27 \\
\mathbf{0 . 0 8} & 0.27\end{array}$ & \begin{tabular}{ll|}
$\mathbf{0 . 3 9}$ & 0.49 \\
$\mathbf{0 . 3 1}$ & 0.46 \\
$\mathbf{0 . 1 6}$ & 0.36 \\
$\mathbf{0 . 0 8}$ & 0.26 \\
$\mathbf{0 . 0 7}$ & 0.26
\end{tabular} & $\begin{array}{ll}0.25 & 0.44 \\
0.27 & 0.45 \\
0.20 & 0.40 \\
0.11 & 0.31 \\
\mathbf{0 . 1 7} & 0.37\end{array}$ \\
\hline NOISE & & 0.80 & 0.97 & 0.88 \\
\hline $\begin{array}{l}\text { always/often } \\
\text { smts/rarely } \\
\text { never }\end{array}$ & \begin{tabular}{||ll|}
-0.112 * & 0.059 \\
BASE & \\
-0.084 & 0.069 \\
\end{tabular} & $\begin{array}{ll}\mathbf{0 . 2 0} & 0.40 \\
\mathbf{0 . 6 8} & 0.47 \\
\mathbf{0 . 1 3} & 0.33 \\
\end{array}$ & \begin{tabular}{ll|}
$\mathbf{0 . 1 8}$ & 0.39 \\
$\mathbf{0 . 6 9}$ & 0.46 \\
$\mathbf{0 . 1 2}$ & 0.33 \\
\end{tabular} & $\begin{array}{ll}\mathbf{0 . 2 4} & 0.43 \\
\mathbf{0 . 6 1} & 0.49 \\
\mathbf{0 . 1 5} & 0.35\end{array}$ \\
\hline SMOKE & & 0.80 & 0.97 & 0.88 \\
\hline $\begin{array}{l}\text { always/often } \\
\text { smts/rarely } \\
\text { never }\end{array}$ & \begin{tabular}{|lr|}
$-0.215^{* *}$ & 0.084 \\
-0.040 & 0.051 \\
\multicolumn{2}{|c|}{ BASE } \\
\end{tabular} & $\begin{array}{ll}\mathbf{0 . 0 8} & 0.27 \\
\mathbf{0 . 3 4} & 0.47 \\
\mathbf{0 . 5 9} & 0.49 \\
\end{array}$ & $\begin{array}{ll}\mathbf{0 . 0 7} & 0.25 \\
\mathbf{0 . 3 3} & 0.47 \\
\mathbf{0 . 6 1} & 0.49 \\
\end{array}$ & $\begin{array}{ll}0.12 & 0.33 \\
0.31 & 0.46 \\
0.57 & 0.50 \\
\end{array}$ \\
\hline FUMES & & 0.98 & 0.99 & 0.98 \\
\hline \begin{tabular}{|l|} 
no \\
yes \\
\end{tabular} & \begin{tabular}{|cc|}
\multicolumn{2}{|c|}{ BASE } \\
-0.101 & 0.064 \\
\end{tabular} & $\begin{array}{ll}\mathbf{0 . 8 8} & 0.32 \\
\mathbf{0 . 1 2} & 0.32 \\
\end{array}$ & $\begin{array}{|ll|}\mathbf{0 . 8 7} & 0.34 \\
\mathbf{0 . 1 3} & 0.34 \\
\end{array}$ & $\begin{array}{lll}\mathbf{0 . 8 4} & 0.37 \\
\mathbf{0 . 1 6} & 0.37 \\
\end{array}$ \\
\hline TRAVMODE & & 0.78 & 0.94 & 0.87 \\
\hline $\begin{array}{l}\text { by foot } \\
\text { public transport } \\
\text { bicycle } \\
\text { car } \\
\text { work at home } \\
\text { other } \\
\text { Joint test of work- } \\
\text { related variables: } \\
\text { Past pregnancies } \\
\end{array}$ & \begin{tabular}{||cc|}
$-0.280^{* * *}$ & 0.076 \\
$-0.180^{* *}$ & 0.078 \\
$-0.777^{* * *}$ & 0.223 \\
BASE & \\
$0.431^{* * *}$ & 0.150 \\
-0.122 & 0.078 \\
& \\
chi2 $2(14)=113.82$ \\
Prob $>$ chi2 $=0.0000$
\end{tabular} & $\begin{array}{ll}\mathbf{0 . 0 9} & 0.29 \\
\mathbf{0 . 1 1} & 0.32 \\
\mathbf{0 . 0 1} & 0.09 \\
\mathbf{0 . 6 6} & 0.47 \\
\mathbf{0 . 0 3} & 0.16 \\
\mathbf{0 . 1 0} & 0.30\end{array}$ & $\begin{array}{ll}\mathbf{0 . 0 8} & 0.26 \\
\mathbf{0 . 1 0} & 0.30 \\
\mathbf{0 . 0 1} & 0.08 \\
\mathbf{0 . 7 0} & 0.46 \\
\mathbf{0 . 0 3} & 0.16 \\
\mathbf{0 . 1 0} & 0.30\end{array}$ & $\begin{array}{ll}\mathbf{0 . 1 6} & 0.37 \\
\mathbf{0 . 1 2} & 0.32 \\
\mathbf{0 . 0 2} & 0.13 \\
\mathbf{0 . 5 7} & 0.49 \\
\mathbf{0 . 0 2} & 0.15 \\
\mathbf{0 . 1 1} & 0.31\end{array}$ \\
\hline MISCARRIAGE & & 0.98 & 0.98 & 0.98 \\
\hline \begin{tabular}{|l} 
no \\
yes
\end{tabular} & 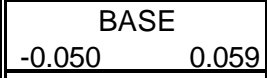 & $\begin{array}{ll}0.79 & 0.41 \\
0.21 & 0.41 \\
\end{array}$ & $\begin{array}{ll}0.82 & 0.38 \\
0.18 & 0.38 \\
\end{array}$ & $\begin{array}{lll}0.76 & 0.43 \\
0.24 & 0.43 \\
\end{array}$ \\
\hline PREVBWEIGHT & & 0.54 & 0.39 & 0.63 \\
\hline \begin{tabular}{|l|} 
no \\
yes \\
\end{tabular} & 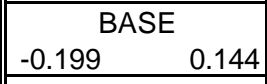 & $\begin{array}{ll}0.93 & 0.26 \\
0.07 & 0.26 \\
\end{array}$ & $\begin{array}{lll}0.94 & 0.24 \\
0.06 & 0.24 \\
\end{array}$ & $\begin{array}{ll}0.92 & 0.27 \\
0.08 & 0.27 \\
\end{array}$ \\
\hline PREMATURE & & 0.54 & 0.39 & 0.63 \\
\hline $\begin{array}{l}\text { no } \\
\text { yes } \\
\text { Joint test of past } \\
\text { pregnancy variables: }\end{array}$ & \begin{tabular}{||c|}
\multicolumn{2}{|c|}{ BASE } \\
0.024 \\
chi2(6)=7.62 \\
Prob $>$ chi2 $=0.131$ \\
\end{tabular} & $\begin{array}{ll}0.91 & 0.28 \\
0.09 & 0.28\end{array}$ & $\begin{array}{ll}0.92 & 0.27 \\
0.08 & 0.27\end{array}$ & $\begin{array}{ll}0.91 & 0.29 \\
0.09 & 0.29\end{array}$ \\
\hline
\end{tabular}




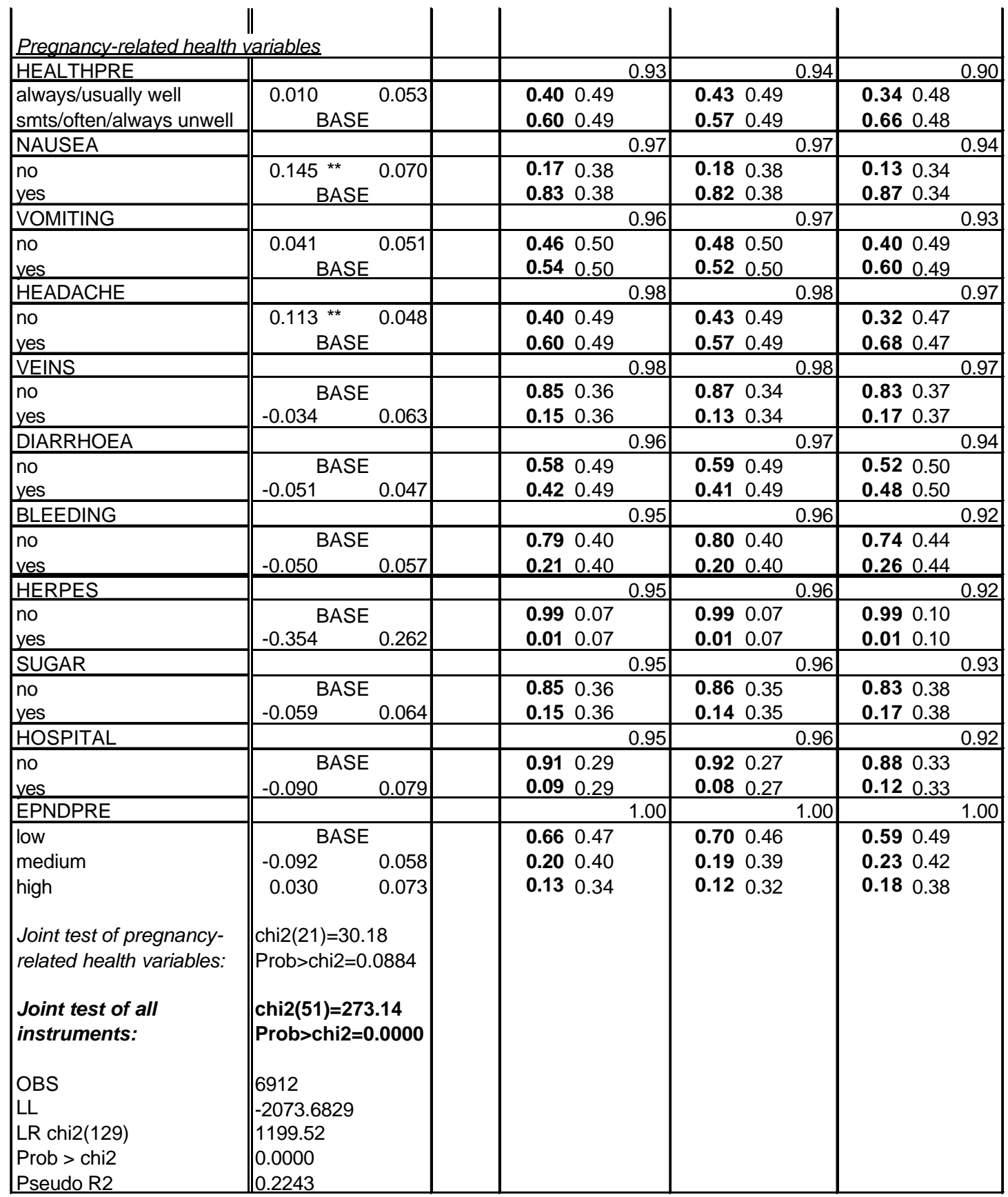

Mean probability of entitlement those with rights $\quad 0.897$

those without rights $\quad 0.693$

$\mathrm{R}=$ response rate to question

***, ${ }^{* *}$ and ${ }^{*}$ indicate significance at the $1 \%, 5 \%$ and $10 \%$ levels respectively 
Appendix A:

Table A1: Variables used in analysis

\begin{tabular}{|c|c|c|}
\hline Variable & Description & $\begin{array}{l}\text { \# of } \\
\text { d.v.'s* }\end{array}$ \\
\hline & Dependent variable & \\
\hline \multirow[t]{2}{*}{ RETTIME } & Age of child in months at return to work (censored at 34 months) & \\
\hline & Explanatory variables & \\
\hline & Basic demographics & \\
\hline AGE & Age of mother at birth & 3 \\
\hline RACE & Mother's ethnicity & 1 \\
\hline ADULTS & Number of over 16 year olds in household at 8 weeks gestation & 2 \\
\hline OLDER SIBS & Number of 0 to 15 year olds in household at 8 weeks gestation & 3 \\
\hline INTERVAL & Interpregnancy interval & 3 \\
\hline \multirow[t]{2}{*}{ YSIBS } & $\begin{array}{l}\text { Number of full-term or incomplete pregnancies in the } 34 \text { months after birth of } \\
\text { study child }\end{array}$ & 2 \\
\hline & Social and financial capital & \\
\hline OCCUPATION & Mother's social class defined according to last occupation & 2 \\
\hline EDUCATION & Mother's highest educational qualification & 2 \\
\hline SEX & Sex of baby (including category for multiple births) & 2 \\
\hline HOURS & Type of work (i.e. PT/FT) in mother's current or last job & 2 \\
\hline HOMESTATUS & Housing tenure at 8 weeks gestation & 3 \\
\hline PTRPRESENT & Whether mother has a live-in partner at 8 weeks gestation & 2 \\
\hline PTREMP8W & Partner's employment situation 8 weeks after the birth & 2 \\
\hline PTREDUC & Partner's highest educational qualification & 2 \\
\hline PTROCCUPATION & Partner's social class defined according to last occupation & 2 \\
\hline PHEALTH & Mother's report of partner's physical health at 8 weeks gestation & 2 \\
\hline GFHTREDUC & Mother's father's highest educational qualification & 2 \\
\hline GMTHREDUC & Mother's mother's highest educational qualification & 2 \\
\hline WLESCHILD & Weighted life event score for mother's life until 17 & 4 \\
\hline SCHOOLS & Number of schools attended by mother up to 16 & 3 \\
\hline \multirow[t]{2}{*}{ WLES8M } & Weighted life event score for the 8 months after the birth & 4 \\
\hline & Mother's health & \\
\hline HLTH8M & Mother's report of own health at 8 months & 1 \\
\hline \multirow[t]{2}{*}{ EPND } & Edinburgh Post-Natal Depression Score at 8 weeks after the birth & 2 \\
\hline & Attitudes & \\
\hline INTENT & Whether pregnancy was intentional & 1 \\
\hline \multirow[t]{3}{*}{ MINAGE } & $\begin{array}{l}\text { Youngest age mother thinks it is alright to leave child regularly in care of } \\
\text { another during the day }\end{array}$ & 6 \\
\hline & Instrumental variables & \\
\hline & Events in pregnancy & \\
\hline TIMEAVON & $\begin{array}{l}\text { Whether the mother had lived in Avon for less than a year at } 8 \text { weeks } \\
\text { gestation }\end{array}$ & 1 \\
\hline MOVED & $\begin{array}{l}\text { Whether mother moved house during pregnancy and if so, whether her } \\
\text { partner simultaneously started a new job }\end{array}$ & 2 \\
\hline \multirow[t]{2}{*}{ WLESPRE } & Weighted life events score for the period of pregnancy & 4 \\
\hline & Work related variables & \\
\hline NOISE & Whether the mother's last workplace before the birth was noisy & 2 \\
\hline SMOKE & Whether the mother's last workplace before the birth was smoky & 2 \\
\hline
\end{tabular}




\begin{tabular}{|c|c|c|}
\hline FUMES & $\begin{array}{l}\text { Whether the mother was exposed to chemicals or fumes in her last workplace } \\
\text { before the birth }\end{array}$ & 1 \\
\hline \multirow[t]{2}{*}{ TRAVMODE } & $\begin{array}{l}\text { The usual mode of travel used by the mother to and from work in her last } \\
\text { workplace before the birth }\end{array}$ & 5 \\
\hline & Previous pregnancies & \\
\hline MISCARRIAGE & Whether the mother had previously had a miscarriage & 1 \\
\hline PREVBWEIGHT & Whether the mother had previously had a baby weighing less that $5 \mathrm{lb} 80 \mathrm{z}$ & 1 \\
\hline \multirow[t]{2}{*}{ PREMATURE } & Whether the mother had ever had a baby born more than 3 weeks early & 1 \\
\hline & Health related pregnancy variables & \\
\hline HEALTHPRE & Mother's report of own health during pregnancy & 1 \\
\hline NAUSEA & Whether the mother suffered from nausea during pregnancy & 1 \\
\hline VOMITING & Whether the mother suffered from vomiting during pregnancy & 1 \\
\hline HEADACHE & Whether the mother suffered from headaches during pregnancy & 1 \\
\hline VEINS & Whether the mother suffered from varicose veins during pregnancy & 1 \\
\hline DIARRHOEA & Whether the mother suffered from diarrhoea during pregnancy & 1 \\
\hline BLEEDING & Whether the mother suffered from vaginal bleeding during pregnancy & 1 \\
\hline HERPES & Whether the mother suffered from herpes during pregnancy & 1 \\
\hline SUGAR & Whether the mother suffered from sugar in the urine during pregnancy & 1 \\
\hline HOSPITAL & Whether mother was admitted to hospital during pregnancy & 1 \\
\hline EPNDPRE & Edinburgh Post-Natal Depression Score in pregnancy & 2 \\
\hline Notes: & ${ }^{*}$. Number of dummy variables excluding base case and missing category. & \\
\hline
\end{tabular}


Table A2: Means and standard deviations of variables

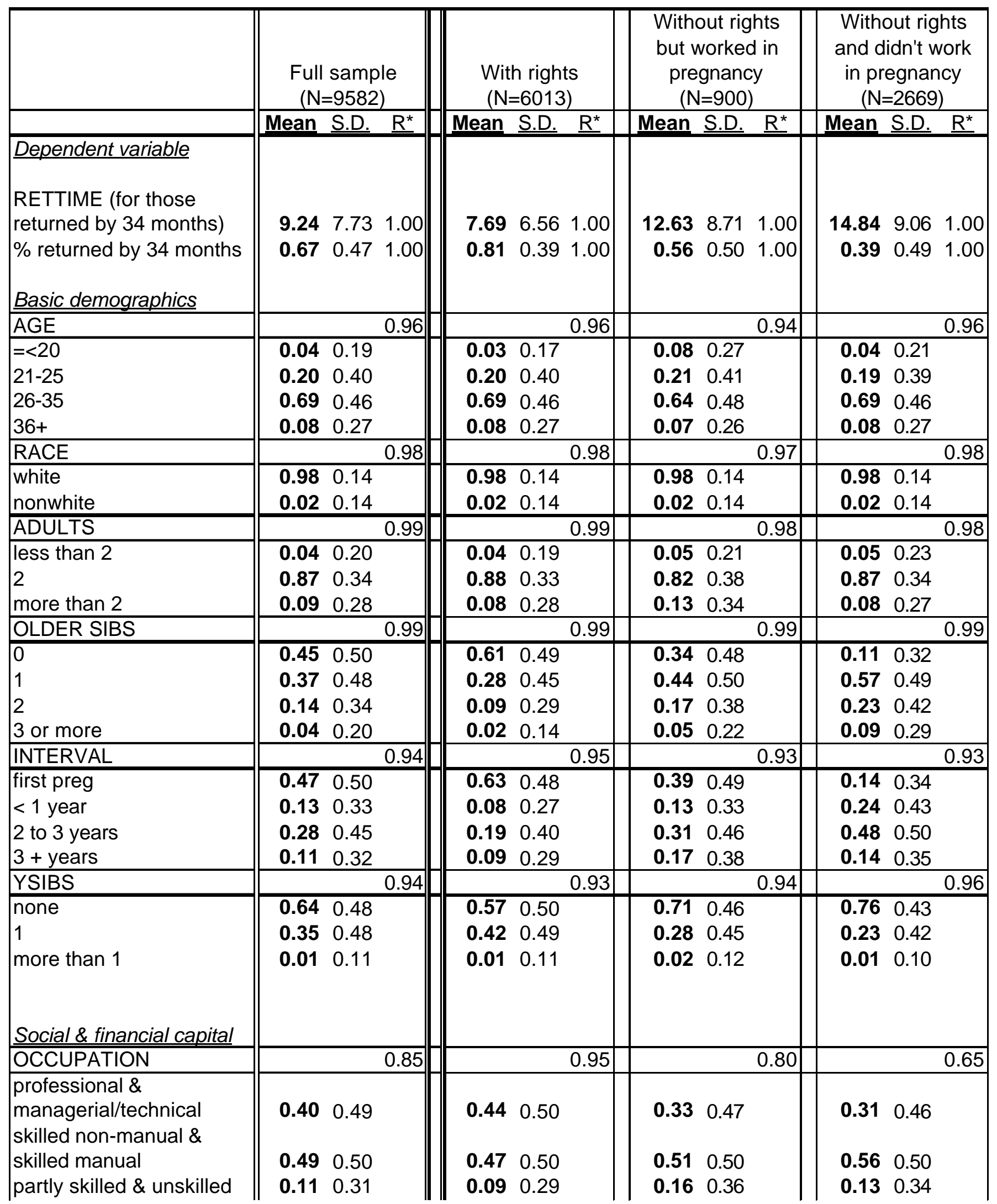




\begin{tabular}{|c|c|c|c|c|}
\hline EDUCATION & 0.98 & 0.98 & 0.97 & 0.98 \\
\hline cse/none & 0.160 .36 & $\begin{array}{ll}0.11 & 0.32\end{array}$ & 0.200 .40 & $\begin{array}{ll}0.23 & 0.42\end{array}$ \\
\hline vocational/o-level & 0.450 .50 & $0.43 \quad 0.50$ & $0.50 \quad 0.50$ & $\mathbf{0 . 4 7} \quad 0.50$ \\
\hline a-level/higher & $\mathbf{0 . 3 9} 0.49$ & 0.450 .50 & $0.30 \quad 0.46$ & 0.290 .45 \\
\hline HOURS & 0.94 & 0.96 & 0.95 & 0.88 \\
\hline $\mathrm{ft}$ & $0.64 \quad 0.48$ & $\begin{array}{ll}0.66 & 0.47\end{array}$ & 0.370 .48 & $0.70 \quad 0.46$ \\
\hline pt & 0.320 .47 & 0.320 .47 & 0.540 .50 & $0.26 \quad 0.44$ \\
\hline casually & $0.03 \quad 0.18$ & 0.020 .15 & 0.090 .29 & 0.040 .19 \\
\hline HOMESTATUS & 0.98 & 0.98 & 0.98 & 0.97 \\
\hline owner-occupied & $0.80 \quad 0.40$ & $\begin{array}{ll}0.87 & 0.34\end{array}$ & $\begin{array}{ll}0.66 & 0.47\end{array}$ & 0.690 .46 \\
\hline council/ha rented & $\mathbf{0 . 1 1} 0.31$ & $0.06 \quad 0.23$ & $\begin{array}{ll}0.16 & 0.37\end{array}$ & 0.210 .41 \\
\hline private rented & $\mathbf{0 . 0 6} 0.24$ & 0.050 .22 & 0.130 .33 & 0.070 .25 \\
\hline other & $0.03 \quad 0.17$ & 0.030 .16 & $\mathbf{0 . 0 4} 0.21$ & $0.03 \quad 0.17$ \\
\hline PTRPRESENT & 0.95 & 0.96 & 0.93 & 0.93 \\
\hline no ptr & $\begin{array}{ll}0.02 & 0.14\end{array}$ & $0.02 \quad 0.12$ & $\begin{array}{|ll|}0.03 & 0.17\end{array}$ & $0.02 \quad 0.15$ \\
\hline lives with ptr & $0.94 \quad 0.24$ & $0.94 \quad 0.23$ & 0.910 .29 & $0.93 \quad 0.25$ \\
\hline doesn't live with & $\mathbf{0 . 0 4} 0.21$ & $0.04 \quad 0.20$ & $0.06 \quad 0.24$ & $0.05 \quad 0.21$ \\
\hline PTREMP8W & 0.94 & 0.95 & 0.93 & 0.93 \\
\hline No working ptr & $\begin{array}{ll}\mathbf{0 . 1 1} & 0.31\end{array}$ & $\begin{array}{ll}0.08 & 0.27\end{array}$ & $0.14 \quad 0.35$ & $\begin{array}{ll}0.16 & 0.37\end{array}$ \\
\hline Has working ptr & 0.870 .34 & $0.90 \quad 0.30$ & 0.810 .39 & $0.80 \quad 0.40$ \\
\hline No ptr & $0.03 \quad 0.17$ & 0.020 .14 & $0.05 \quad 0.21$ & $0.04 \quad 0.19$ \\
\hline PTREDUC & 0.96 & 0.96 & 0.94 & 0.95 \\
\hline cse/none & $\begin{array}{ll}0.21 & 0.41\end{array}$ & $\begin{array}{ll}0.18 & 0.38\end{array}$ & 0.250 .43 & 0.270 .44 \\
\hline vocational/o-level & 0.290 .46 & 0.300 .46 & 0.300 .46 & 0.270 .45 \\
\hline a-level/higher & $0.48 \quad 0.50$ & 0.510 .50 & 0.420 .49 & 0.440 .50 \\
\hline no ptr & $0.02 \quad 0.14$ & 0.020 .12 & $\begin{array}{ll}0.03 & 0.17\end{array}$ & $0.02 \quad 0.15$ \\
\hline PTROCCUPATION & 0.93 & 0.94 & 0.92 & 0.91 \\
\hline professional \& & $046 \cap 50$ & 018050 & $011 \cap 19$ & 044050 \\
\hline skilled non-manual \& & $0.40 \quad 0.00$ & & & \\
\hline skilled manual & $0.40 \quad 0.49$ & 0.400 .49 & $\mathbf{0 . 4 2} 0.49$ & $0.40 \quad 0.49$ \\
\hline partly skilled \& unskilled & $\mathbf{0 . 1 1} 0.32$ & 0.100 .30 & $\begin{array}{ll}0.14 & 0.34\end{array}$ & $0.13 \quad 0.34$ \\
\hline no ptr & $\mathbf{0 . 0 2} 0.14$ & 0.020 .13 & $0.03 \quad 0.17$ & $0.02 \quad 0.15$ \\
\hline PHEALTH & 0.98 & 0.98 & 0.97 & 0.97 \\
\hline \begin{tabular}{|l} 
always/usually well \\
\end{tabular} & $\begin{array}{ll}0.94 & 0.23\end{array}$ & $\begin{array}{ll}0.95 & 0.21\end{array}$ & $\begin{array}{ll}0.92 & 0.27\end{array}$ & $\begin{array}{ll}0.93 & 0.25\end{array}$ \\
\hline smts/often/always un & 0.040 .19 & $0.03 \quad 0.17$ & 0.050 .21 & $0.04 \quad 0.21$ \\
\hline no ptr & $0.02 \quad 0.14$ & $0.02 \quad 0.12$ & $0.03 \quad 0.17$ & $0.02 \quad 0.15$ \\
\hline GFTHREDUC & 0.69 & 0.71 & 0.66 & 0.66 \\
\hline cse/none & $\begin{array}{ll}0.39 & 0.49\end{array}$ & $\begin{array}{ll}0.35 & 0.48\end{array}$ & $\begin{array}{ll}0.43 & 0.49\end{array}$ & 0.490 .50 \\
\hline vocational/o-level & $0.34 \quad 0.47$ & 0.350 .48 & 0.330 .47 & 0.290 .46 \\
\hline a-level/higher & $0.27 \quad 0.44$ & 0.300 .46 & $0.24 \quad 0.43$ & 0.220 .41 \\
\hline GMTHREDUC & 0.73 & 0.75 & \begin{tabular}{l|l}
0.72 \\
\end{tabular} & 0.71 \\
\hline cse/none & $\begin{array}{ll}0.45 & 0.50\end{array}$ & $\begin{array}{ll}0.41 & 0.49\end{array}$ & 0.460 .50 & $\begin{array}{ll}0.52 & 0.50\end{array}$ \\
\hline vocational/o-level & $\mathbf{0 . 3 4} 0.47$ & 0.360 .48 & $\mathbf{0 . 3 1} 0.46$ & $0.30 \quad 0.46$ \\
\hline a-level/higher & 0.210 .41 & $0.23 \quad 0.42$ & 0.220 .42 & $0.18 \quad 0.39$ \\
\hline SCHOOLS & 0.93 & 0.94 & 0.93 & 0.94 \\
\hline 2 or less & $\begin{array}{ll}0.43 & 0.49\end{array}$ & $\begin{array}{ll}0.44 & 0.50\end{array}$ & $\begin{array}{ll}\mathbf{0 . 4 1} & 0.49\end{array}$ & $\begin{array}{ll}0.41 & 0.49\end{array}$ \\
\hline 3 & $0.37 \quad 0.48$ & $0.36 \quad 0.48$ & $0.36 \quad 0.48$ & $0.38 \quad 0.49$ \\
\hline 4 & $\mathbf{0 . 1 2} 0.32$ & 0.110 .32 & 0.130 .34 & 0.120 .32 \\
\hline 5 or more & $\mathbf{0 . 0 9} 0.29$ & 0.090 .28 & 0.100 .30 & 0.090 .29 \\
\hline
\end{tabular}




\begin{tabular}{|c|c|c|c|c|}
\hline WLES8M & 0.95 & 0.96 & 0.94 & 0.95 \\
\hline $0-4$ & $\begin{array}{ll}0.29 & 0.46\end{array}$ & 0.250 .44 & $\begin{array}{ll}\mathbf{0 . 3 1} & 0.46\end{array}$ & $\begin{array}{|ll|}\mathbf{0 . 3 8} & 0.49\end{array}$ \\
\hline $5-9$ & $0.30 \quad 0.46$ & 0.310 .46 & 0.290 .45 & 0.270 .45 \\
\hline $10-14$ & 0.180 .39 & 0.200 .40 & $\mathbf{0 . 1 7} 0.38$ & $\begin{array}{ll}0.16 & 0.37\end{array}$ \\
\hline $15-19$ & 0.100 .31 & $\begin{array}{ll}0.11 & 0.32\end{array}$ & $\mathbf{0 . 1 1} 0.32$ & $0.08 \quad 0.27$ \\
\hline $20+$ & 0.120 .32 & 0.120 .33 & $0.13 \quad 0.33$ & 0.100 .30 \\
\hline \multicolumn{5}{|l|}{ Mother's health } \\
\hline HLTH8M & 0.95 & 0.96 & 0.94 & 0.95 \\
\hline $\begin{array}{l}\text { always/mostly well } \\
\text { often unwell/hardly ever }\end{array}$ & $0.95 \quad 0.22$ & $\begin{array}{ll}0.95 & 0.21\end{array}$ & $\begin{array}{ll}0.94 & 0.24\end{array}$ & $\begin{array}{ll}0.94 & 0.24\end{array}$ \\
\hline well & $0.05 \quad 0.22$ & $0.05 \quad 0.21$ & $0.06 \quad 0.24$ & $0.06 \quad 0.24$ \\
\hline EPND & 0.96 & 0.96 & 0.94 & 0.96 \\
\hline Iow & $\begin{array}{ll}0.74 & 0.44\end{array}$ & $\begin{array}{ll}0.77 & 0.42\end{array}$ & $0.70 \quad 0.46$ & $0.70 \quad 0.46$ \\
\hline medium & 0.170 .37 & $\mathbf{0 . 1 6} 0.37$ & 0.190 .39 & $\mathbf{0 . 1 8} \quad 0.39$ \\
\hline high & 0.090 .29 & 0.070 .26 & 0.110 .32 & 0.120 .32 \\
\hline \multicolumn{5}{|l|}{ Child-related variables } \\
\hline SEX & 1.00 & 1.00 & 1.00 & 1.00 \\
\hline male & $\begin{array}{ll}0.51 & 0.50\end{array}$ & $\begin{array}{ll}0.51 & 0.50\end{array}$ & $\begin{array}{ll}0.52 & 0.50\end{array}$ & $\begin{array}{ll}0.51 & 0.50\end{array}$ \\
\hline female & $0.48 \quad 0.50$ & 0.480 .50 & 0.460 .50 & $0.48 \quad 0.50$ \\
\hline multiple birth & 0.010 .11 & 0.010 .11 & 0.010 .11 & 0.010 .11 \\
\hline \multicolumn{5}{|l|}{ Attitudes } \\
\hline INTENT & 0.98 & 0.99 & 0.97 & 0.99 \\
\hline intentional & $\begin{array}{ll}0.73 & 0.45\end{array}$ & $\begin{array}{ll}0.74 & 0.44\end{array}$ & $\begin{array}{ll}0.68 & 0.47\end{array}$ & $\begin{array}{ll}0.71 & 0.46\end{array}$ \\
\hline unintentional & 0.270 .45 & 0.260 .44 & $0.32 \quad 0.47$ & 0.290 .46 \\
\hline MINAGE & 0.97 & 0.97 & 0.96 & 0.97 \\
\hline $0-5 \mathrm{mths}$ & $0.22 \quad 0.42$ & $\begin{array}{ll}0.30 & 0.46\end{array}$ & $\begin{array}{ll}0.15 & 0.35\end{array}$ & $\begin{array}{ll}0.08 & 0.27\end{array}$ \\
\hline 6-11 mths & 0.240 .43 & 0.290 .45 & $0.21 \quad 0.41$ & $\mathbf{0 . 1 4} \quad 0.35$ \\
\hline 1-2 years & $\begin{array}{ll}0.11 & 0.31\end{array}$ & $\begin{array}{lll}0.09 & 0.28\end{array}$ & $\mathbf{0 . 1 4} \quad 0.35$ & $\mathbf{0 . 1 4} 0.35$ \\
\hline 3-4 years & $\begin{array}{ll}0.11 & 0.32\end{array}$ & $0.07 \quad 0.26$ & 0.150 .36 & 0.200 .40 \\
\hline 5 or more years & 0.070 .26 & 0.050 .21 & $\begin{array}{ll}0.08 & 0.27\end{array}$ & $0.13 \quad 0.34$ \\
\hline never & $0.05 \quad 0.22$ & $\begin{array}{ll}0.03 & 0.18\end{array}$ & $0.05 \quad 0.22$ & $0.09 \quad 0.28$ \\
\hline don't know & 0.190 .39 & $\begin{array}{ll}0.17 & 0.37\end{array}$ & 0.220 .41 & 0.220 .42 \\
\hline${ }^{*} \mathrm{R}=$ respons & & & & \\
\hline
\end{tabular}


Table A3: Discrete Hazard Models

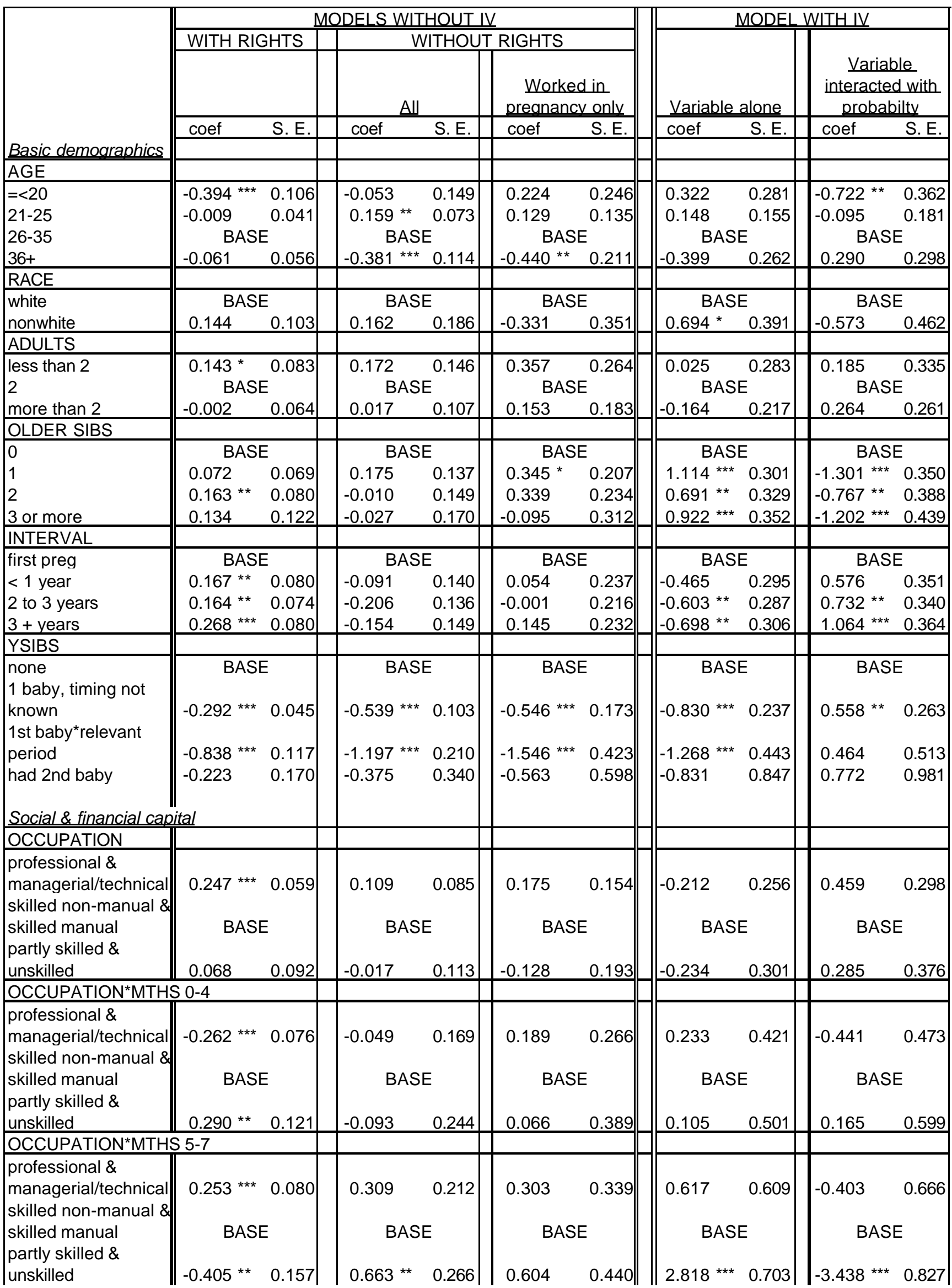




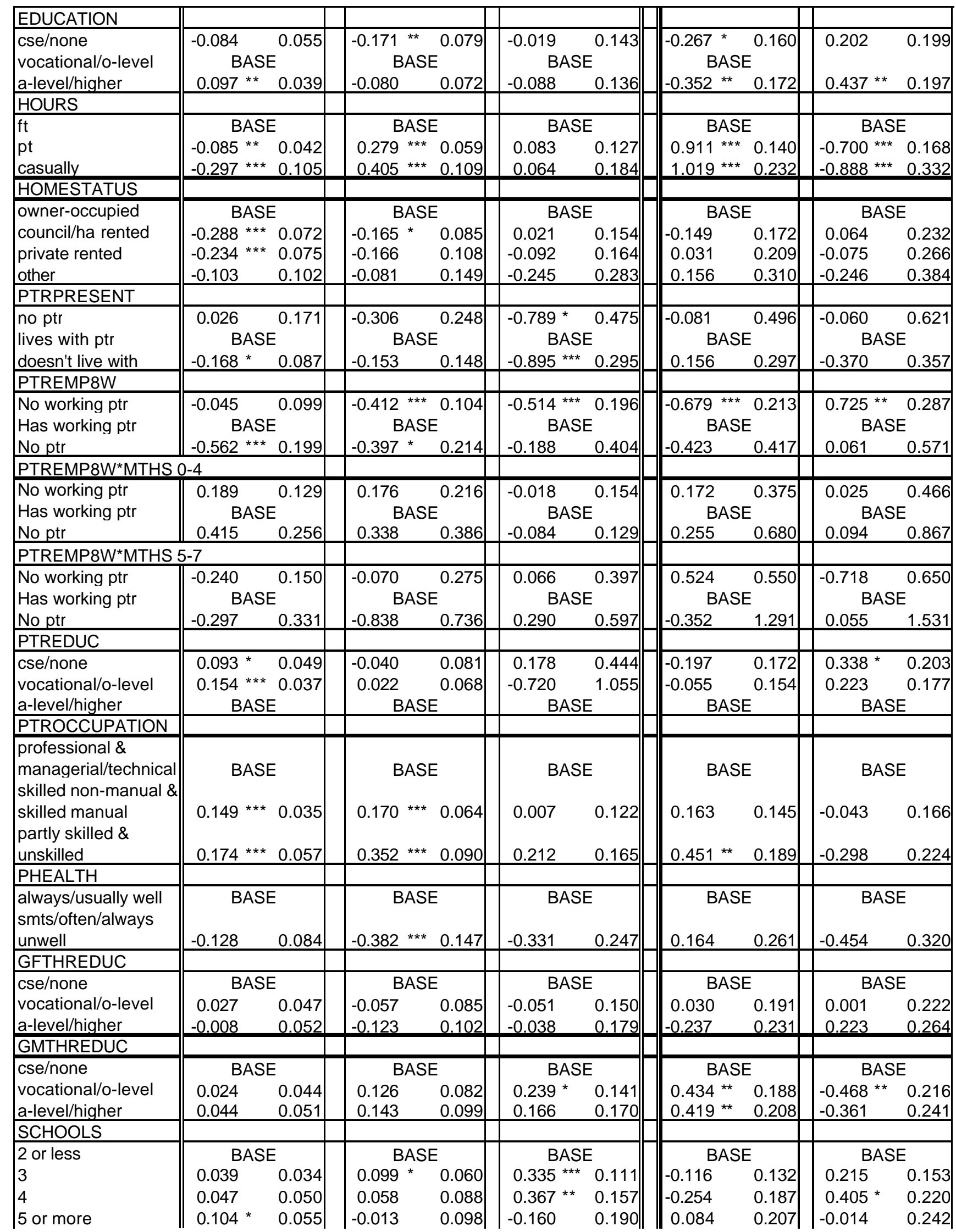




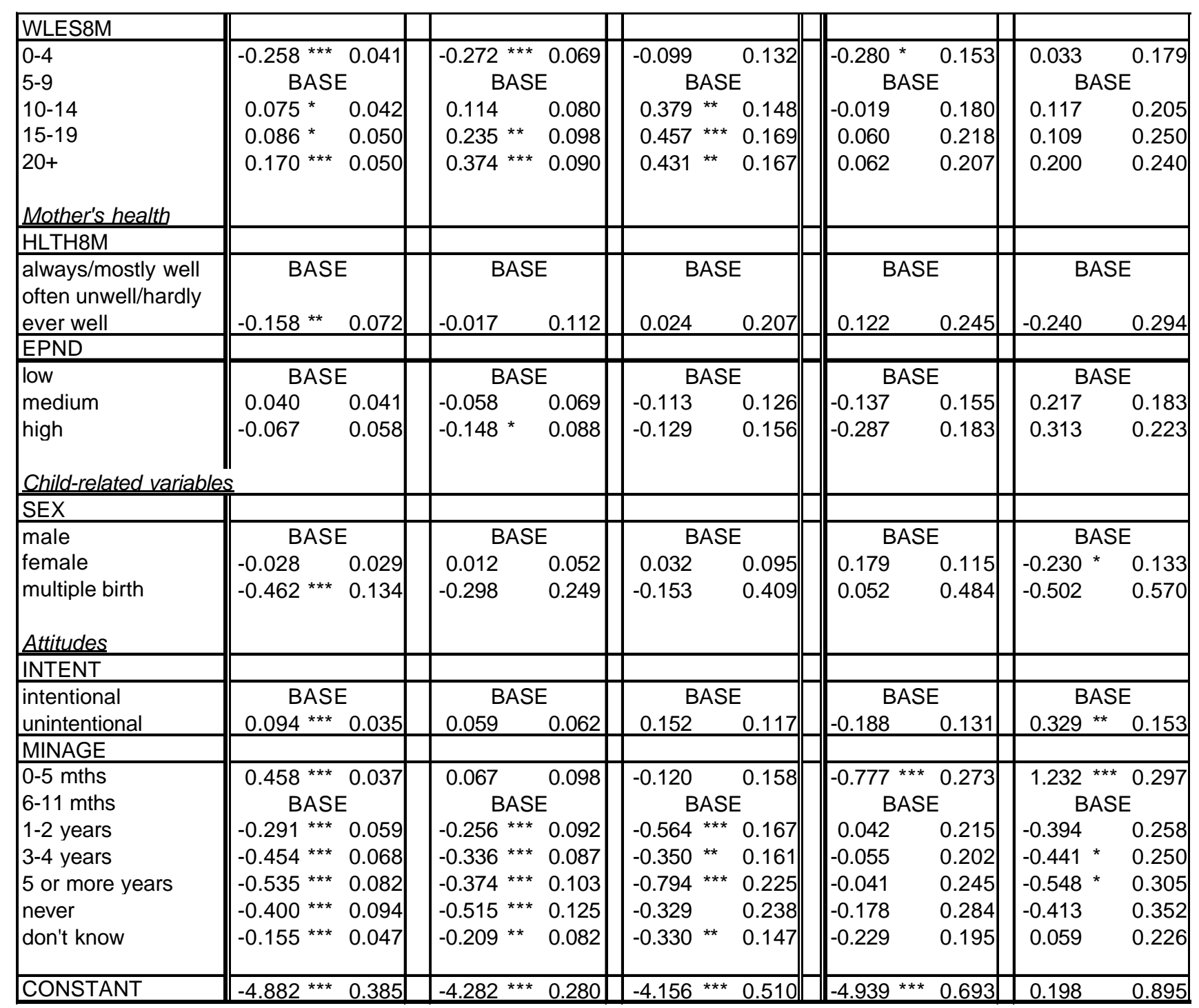

$\begin{array}{lllll}\text { OBS } & -16152.35 & -7393.1419 & -2199.3678 & -23830.98 \\ \text { LL } & 81893 & 94033 & 20645 & 175433 \\ \text { NONZERO } & & & & \\ \text { OUTCOMES } & 4886 & 1553 & 508 & 6436 \\ \text { LR chi2 } & 4717.55 & 1039.26 & 368.68 & 7517.45 \\ \text { Prob > chi2 } & 0.0000 & 0.0000 & 0.0000 & 0.0000\end{array}$

${ }^{* * *},{ }^{* *}$ and * indicate significance at the $1 \%, 5 \%$ and $10 \%$ levels respectively 


\section{Appendix B: Maternity rights in the UK}

The dataset used in our analysis relates to mothers whose expected date of delivery lay between $1^{\text {st }}$ April 1991 and $31^{\text {st }}$ December 1992 . The maternity rights prevailing at this time were as follows:

\section{Maternity leave}

Women had the right to return to the same job at any time up to 29 weeks after the childbirth provided that they had either

- been employed continuously with the same employer for a minimum of two years and worked for at least 16 hours weekly

or

- been employed continuously with the same employer for a minimum of five years

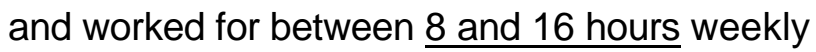

\section{Statutory maternity pay (SMP)}

SMP was payable for a maximum of 18 weeks. To qualify a woman must have worked into the $15^{\text {th }}$ week before her expected delivery date and have paid Class 1 National Insurance contributions. The higher rate of SMP was paid at a rate of $90 \%$ of the woman's usual weekly earnings for the first 6 weeks, followed by a flat-rate payment for a further 12 weeks. To qualify for the higher rate the woman must fulfil either of the two necessary conditions for maternity leave (see above). Women not eligible for higher rate SMP received a flat rate payment for the entire 18-week period, provided that they had worked continuously for the same employer for 6 months. At this time, women had to begin the receipt of SMP before the $6^{\text {th }}$ week prior to the expected delivery date if they were to receive the full amount. 
Maternity Allowance (MA)

Maternity Allowance, which was paid at a flat rate by the DSS for up to 18 weeks, covered some women who were not eligible for SMP. The self-employed who had paid full rate National Insurance contributions in 26 out of the 52 weeks prior to the $15^{\text {th }}$ week before the baby was due were entitled to receive MA. In addition, women with at least 6 months employment out of the 12 months prior to the $14^{\text {th }}$ week before the due date were covered, provided that they had paid full rate National Insurance contributions.

Contractual Maternity Pay (CMP)

CMP is paid by those employers who choose to make maternity payments in addition to the statutory minimum. Each woman's employer establishes the qualifying conditions (which may be more generous than the statutory requirements) and the entitlements (which may relate to the rate of pay, the length of paid leave or the length of unpaid leave).

\section{The current regime}

Currently all employees are entitled to 18 weeks of Ordinary Maternity Leave, regardless of their length of service. Women employed by the same employer for one year prior to the $11^{\text {th }}$ week before the EWC are entitled to Additional Maternity Leave, which extends up to 29 weeks after the birth. Mothers may begin their maternity leave or payments at any time from the $11^{\text {th }}$ week before the expected delivery date. 
The conditions for receipt of SMP have been relaxed so that all women continuously employed by the same employer for 26 weeks (prior to the $15^{\text {th }}$ week before the due date) are covered, provided their average weekly earnings in the final 8 weeks exceed the lower earnings limit for National Insurance contributions. In addition, all women who qualify are now entitled to receive $90 \%$ of weekly earnings for the first 6 weeks. Maternity Allowance is still payable for 18 weeks to some of the women not covered by SMP and the qualifying conditions for receipt of MA have also been loosened.

\section{The government's proposals for reform}

In the 2001 Budget, the government increased the length of the SMP period from 18 to 26 weeks (the $90 \%$ rate still applies for the first 6 weeks only) with effect from April 2003. With regard to leave, the government has proposed to introduce 26 weeks of unpaid leave to run from the end of the 26 weeks paid leave, instead of 29 weeks from the date of birth. This fixes the total leave period (paid and unpaid) at one year. The government's proposals also contain some measures to encourage the acceptance of flexible working patterns for parents of young children by employers and also to extend the benefit rights of fathers on paternity leave. 